\title{
A Noise and Emissions Assessment of the N3-X Transport
}

\author{
Jeffrey J. Berton $^{*}$ and William J. Haller ${ }^{\dagger}$ \\ NASA Glenn Research Center, Cleveland, Ohio 44135
}

\begin{abstract}
Analytical predictions of certification noise and exhaust emissions for NASA's N3-X - a notional, hybrid wingbody airplane - are presented in this paper. The N3-X is a 300passenger concept transport propelled by an array of fans distributed spanwise near the trailing edge of the wingbody. These fans are driven by electric motors deriving power from twin generators driven by turboshaft engines. Turboelectric distributed hybrid propulsion has the potential to dramatically increase the propulsive efficiency of aircraft. The noise and exhaust emission estimates presented here are generated using NASA's conceptual design systems analysis tools with several key modifications to accommodate this unconventional architecture. These tools predict certification noise and the emissions of oxides of nitrogen by leveraging data generated from a recent analysis of the N3-X propulsion system.
\end{abstract}

\section{Nomenclature}

$\begin{array}{llll}a_{i} & =\text { empirical regression constants } & M & =\text { Mach number } \\ A & =\text { area } & N_{E} & =\text { number of engines } \\ A R & =\text { slot nozzle aspect ratio } & N_{F} & =\text { Fresnel number } \\ c & =\text { speed of sound } & p & =\text { pressure } \\ C & =\text { combustor liner cooling air fraction } & S t & =\text { Strouhal number } \\ d & =\text { diameter } & T & =\text { temperature } \\ E I & =\text { emission index } & V & =\text { velocity } \\ f & =\text { frequency or fuel-air ratio } & W & =\text { slot nozzle exit width } \\ F & =\text { slot nozzle noise correction term } & \Delta & =\text { Fresnel number characteristic length } \\ G & =\text { slot nozzle geometry factor } & \zeta & =\text { acoustic impedance ratio } \\ H & =\text { slot nozzle exit height } & \theta & =\text { polar (yaw) angle } \\ L & =\text { length } & \lambda & =\text { wavelength } \\ L_{I} & =\text { insertion loss } & \phi & =\text { azimuthal (roll) angle }\end{array}$

\section{Introduction}

$\mathrm{T}$

The N3-X concept vehicle is an innovative notional aircraft employing a number of electric motors that drive propulsor fans distributed along the trailing edge of the hybrid wingbody planform. The propulsors ingest the thick boundary layer flow atop the planform, partially fill the wake created by the vehicle, and reduce the thrust required to move the vehicle. The power required by these electric motors is generated by two turboshaft-enginedriven electric generators located on each wingtip. This arrangement enables the use of many small, distributed propulsors, allowing for a very high effective bypass ratio while retaining the higher efficiency of large core engines. The turboelectric generators are connected to the propulsors via cooled, superconducting electric power lines.

The N3-X carries a payload of 300 passengers in three classes, cruises at Mach 0.84, and has a design range of $7500 \mathrm{~nm}$. Additional details of the N3-X vehicle and its unique propulsion system may be found in Refs. 1-6. Two views of the N3-X vehicle are shown in Figure 1.

NASA sets aggressive, strategic, civil aircraft performance and environmental goals that require an ambitious technology roadmap for U.S. aerospace industry. Under NASA's Fundamental Aeronautics Program, the Fixed Wing Project has adopted fuel efficiency, community noise, and exhaust emissions goals for the subsonic civil aircraft expected to achieve a technology readiness level ${ }^{7}$ of 4 to 6 by 2025. In NASA vernacular, these aircraft are

\footnotetext{
*Aerospace Engineer, Multidisciplinary Design, Analysis and Optimization Branch, MS 5-11, senior member AIAA.

${ }^{\dagger}$ Aerospace Engineer, Multidisciplinary Design, Analysis and Optimization Branch, MS 5-11.
} 
designated " $\mathrm{N}+3$ " vehicles since they represent the possible third generation of successors to the current, in-service, "N" airplanes. The N3-X is one of several concept vehicles for the $\mathrm{N}+3$ timeframe being examined by NASA internally and under contract.

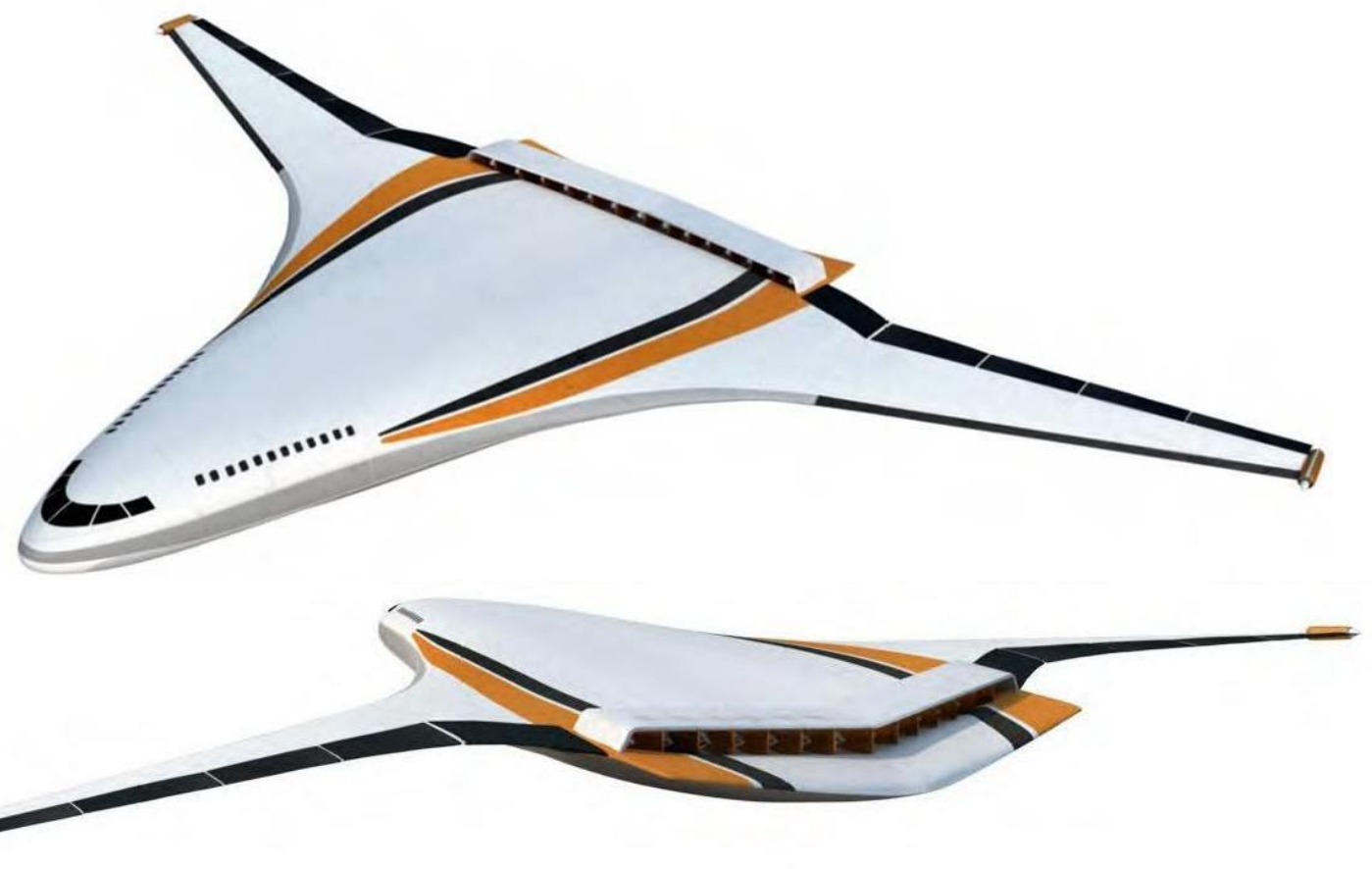

Figure 1. Two views of the N3-X vehicle as envisioned in References 1-6, showing the arrangement of propulsors and wingtip-mounted turboshaft engines (Graphics: NASA).

For the N+3 timeframe, NASA's Fixed Wing Project has set a goal for block fuel burn reduction of $60 \%$ relative to 2005 best-in-class performance levels. Preliminary calculations indicate that the N3-X would be able to meet this fuel burn goal. ${ }^{5}$ Also, the goal for reduction of oxides of nitrogen $\left(\mathrm{NO}_{\mathrm{X}}\right)$ is set to $80 \%$ below the landing and takeoff emission limits set in 2004 by the Committee on Aviation Environmental Protection (CAEP/6) ${ }^{8,9}$ Additionally, N+3 aircraft are hoped to achieve a goal in certification noise of 52 cumulative EPNdB under current FAA Stage $4^{10}$ and ICAO Chapter $4^{11}$ noise limits."

Predictions of noise and exhaust emissions relative to these NASA goals are the focus of this paper. The latest engine and vehicle information and the best available conceptual methods are used. Several key modifications to NASA's noise analysis tools are necessary to predict the noise of this unconventional architecture. These modifications, as well as summaries of NASA's conventional system performance prediction practices, are discussed in the following sections. In many cases, analytical methods best-suited for conventional aircraft are extended to the highly unconventional characteristics of the N3-X. These analytical shortcomings are noted in the sections below as they arise. This assessment is the first attempt at predicting the noise and exhaust emissions of the N3-X using simpler tools until more accurate methods become available.

\section{Method of Analysis}

Two variants of the N3-X are analyzed for the noise prediction portion of this task. Both of the variations are slightly different than the version of the vehicle as envisioned in References 1-6. The first variant uses thrust vectoring for pitch control rather than the large horizontal pitch effector control surface aft of the propulsor slot nozzles as sketched in Figure 1. The pitch effector was eliminated over concerns that it would result in higher jet noise levels and jeopardize achieving the project's noise goal. Research into "beveled nozzles" (i.e., nozzles having rectangular exits with a horizontal surface extending beyond the nozzle exit plane) indicates that the jet plume scrubbing over the extension increases the noise level by a few decibels (e.g., Bridges ${ }^{12}$ ), unless the extension is very long (see, e.g., Coles ${ }^{13}$ ). Since the N3-X pitch effector is similar to the bevels fabricated for Bridges' study, it was thought that jet noise would increase by an amount similar to the levels measured in the experiment. Therefore,

*The cumulative noise level is the algebraic sum of the three certification noise levels.

2 of 22

American Institute of Aeronautics and Astronautics 
the first N3-X variant is a configuration where the pitch control surface is replaced by vectoring nozzles that exit at the trailing edge of the wingbody. This design is similar in function to the Silent Aircraft Initiative SAX-40 or the HSeries hybrid wingbodies proposed by the Massachusetts Institute of Technology. The first N3-X variant is shown in Figure 2 (top).

The second N3-X configuration was envisioned to address problems that became evident after the noise levels of the first configuration were examined. It will be shown in Section III below that the noise predicted for the first configuration did not meet the project goal. The dominant noise sources were the core noise levels of the wingtip turboshaft engines at the lateral and flyover monitors, and the noise of the high-lift flap system at the approach monitor. The noise levels of these two sources needed to be addressed if the vehicle were to meet the project noise goal. Thus, a special "low-noise" version of the N3-X was proposed and investigated. The loud turboshaft engines were relocated from the wingtips to an alternate location; perhaps somewhere on the upper surface of the planform where they could enjoy shielding from the large wingbody planform, or perhaps embedded inside the wingbody volume with inlet and exhaust ducts long enough where acoustic treatment could reduce the core noise to acceptable levels. In the original configuration, the turboshaft engines were located on the wingtips to provide wing bendingmoment relief and to reduce wingtip vortices and lift-dependent drag. In this variant with relocated turboshaft engines, winglets would presumably occupy the wingtip positions. Further, in the assessment of the first variant, the slot nozzle jet noise was found to be lower than the propulsor fan discharge noise. Thus, for the second variant, the horizontal pitch effector was reintroduced - and the resulting increase in slotted jet noise tolerated - in order to provide additional noise shielding for the fans. Last, the conventional slotted flap system was replaced with lownoise, slotless flaperons to address the noise at approach. This low-noise version of the N3-X is shown in Figure 2 (bottom). All of these design alterations are made for the sake of noise, while the exhaust $\mathrm{NO}_{\mathrm{X}}$ emission predictions are unaffected.
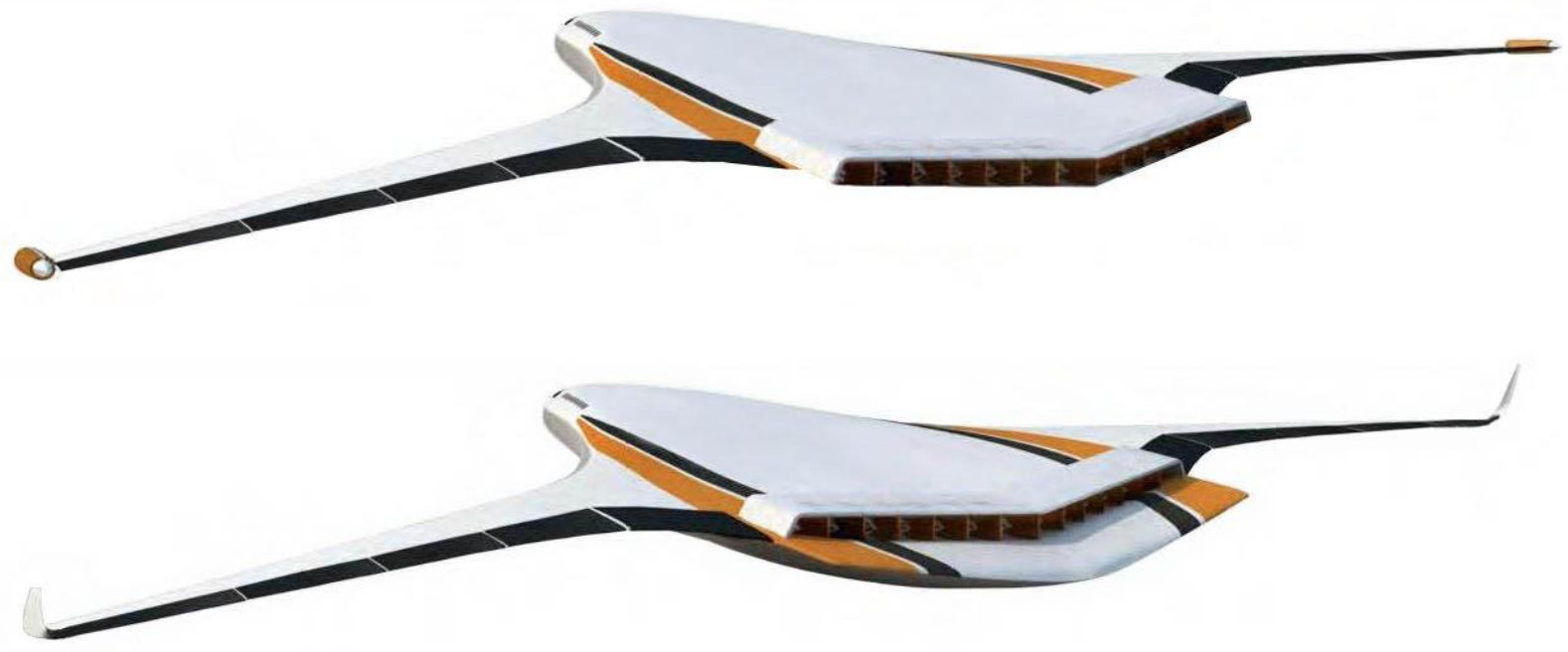

Figure 2. Two versions of N3-X vehicle: initial thrust-vectoring configuration (top); and the alternate lownoise configuration with relocated turboshaft engines (bottom) (Graphics: NASA).

The system-level certification noise prediction tool used for this analysis is the Aircraft Noise Prediction Program (ANOPP, Release Level 30). ${ }^{14,15}$ Freefield, lossless, $1 / 3^{\text {rd }}$ octave band frequency component source noise levels are computed using predictive modules within ANOPP or using modifications to these methods as described in later sections. The N3-X engine's thermodynamic, aeromechanical, and geometry data are used as inputs to ANOPP's propulsion source noise prediction methods. Engine state data - consisting of pressure, temperature, flow area, spool speed, and fuel and air flow rates - are computed for a range of airspeeds, altitudes, and throttle settings at standard acoustic day (ISA $+18^{\circ} \mathrm{F}$ ) conditions. As the airplane traverses its flight path, engine data at the appropriate airspeed, altitude, atmospheric conditions, and throttle setting are delivered to the source noise prediction methods.

The foundation for both the certification noise and exhaust emission assessments is the design of the turboelectric propulsion system. The NASA simulation of the propulsion system has evolved over time as the analysis is refined. Analytical iterations between the airframe and the propulsion system during the vehicle sizing process also influence the engine design. The propulsion design was frozen in early 2013 so that the noise and

3 of 22

American Institute of Aeronautics and Astronautics 
emissions predictions could proceed. The frozen engine closely resembles the definition described in Ref. 5, except that there are 12 propulsor fans in this assessment rather than 14 . $^{*}$

The propulsion system is currently modeled at NASA using the Numerical Propulsion System Simulation code $\left(\right.$ NPSS $^{16,17}$ ). NPSS is a variable-fidelity, object-oriented, engine cycle analysis tool developed jointly by NASA and U.S. industry. It is currently the accepted, state-of-the-art software for airbreathing engine cycle performance analysis for U.S. aerospace industry, academia, and NASA. Aeromechanical design, flowpath, and engine weight analyses are performed with the Weight Analysis of Turbine Engines code (WATE ${ }^{18}$ ). WATE has been significantly upgraded since its initial introduction in the 1970s and is currently implemented as a suite of NPSS interpretive analysis elements. At NASA, WATE is coupled with NPSS to provide a complete modeling capability of turbofan engines. The following sections describe how the propulsion data are used for each disciplinary analysis.

\section{A. $\mathrm{NO}_{\mathrm{x}}$ Exhaust Emissions}

Oxides of nitrogen pose a health hazard to animal and plant life and are a potential ozone destruction risk in the stratosphere. In gas turbine engines, they are predominantly produced thermally via the Zeldovich chain reaction when ordinary nitrogen in the air comes into contact with high-temperature regions inside the combustor. There, nitrogen oxidizes into nitric oxide (NO), and much of it subsequently oxidizes further into nitrogen dioxide $\left(\mathrm{NO}_{2}\right)$, which are collectively known as $\mathrm{NO}_{\mathrm{X}} \cdot \mathrm{NO}_{\mathrm{X}}$ is one of the commercial jet engine exhaust emittants regulated by international standards. ${ }^{9}$

The landing and takeoff (LTO) cycle defined in these regulations is intended to represent a single airplane operational cycle near airports. This cycle consists of four operational segments, each having a different throttle setting and time in mode. The parameter regulated, LTO $\mathrm{NO}_{\mathrm{X}}$, is commonly written as $D_{p} / F_{o o}$ in the ICAO literature. $D_{p}$ is the amount of $\mathrm{NO}_{\mathrm{X}}$ generated over the four segments of the operational cycle (in grams), and $F_{o o}$ is the maximum takeoff-rated sea level static thrust (in kilonewtons). The thrust settings and times for the four segments in the landing-takeoff cycle are shown in Figure 3.

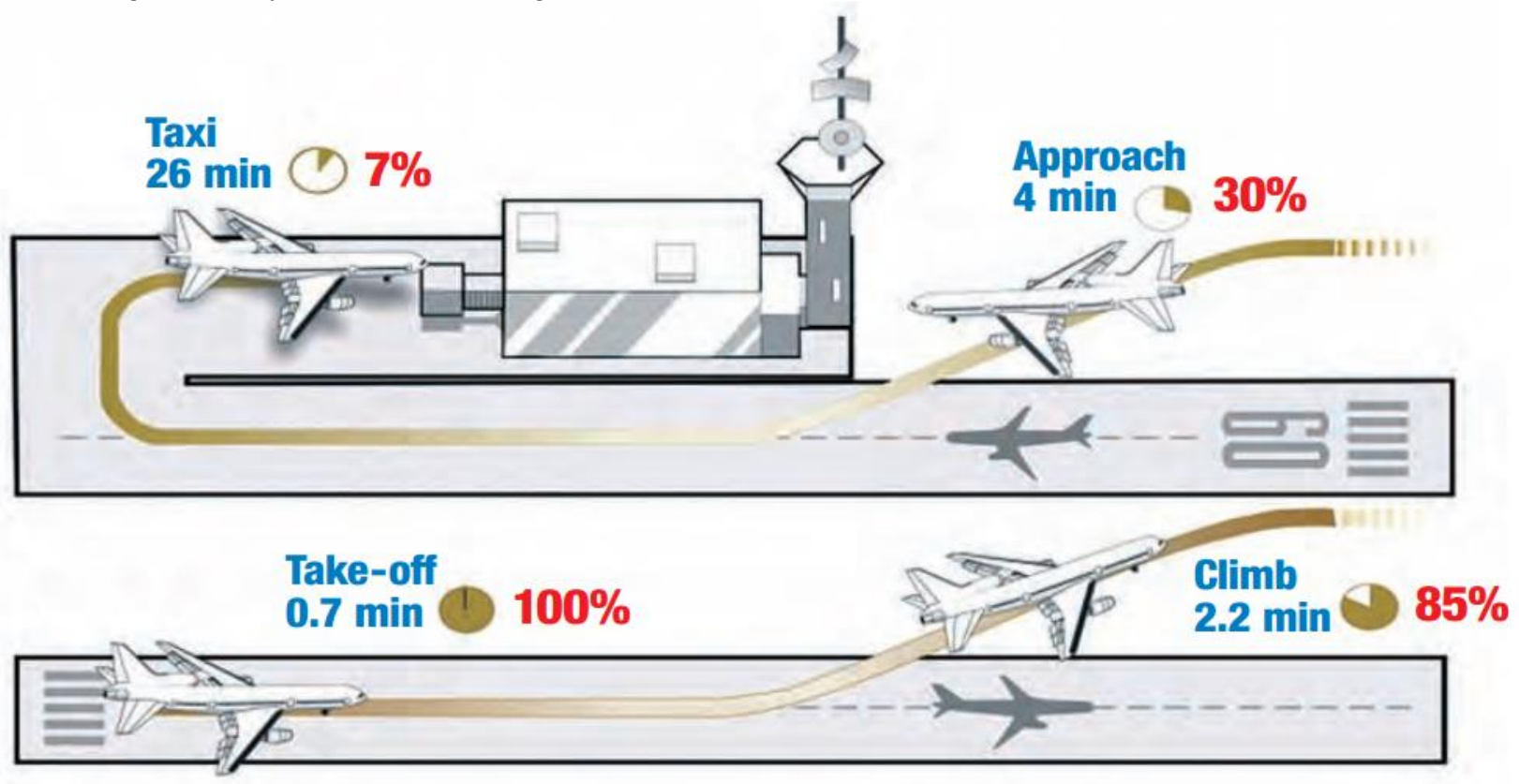

\section{Thrust settings}

Figure 3. $\mathrm{NO}_{\mathrm{X}}$ emissions certification procedure showing thrust settings and times for the four segments in the landing-takeoff cycle (Graphic: ICAO).

The N3-X concept vehicle represents something of a regulatory oddity. Although its propulsor fans are driven by electric motors and would not produce any exhaust emissions themselves, its wingtip turboshafts are gas turbine engines with combustors that burn ordinary jet fuel and produce $\mathrm{NO}_{\mathrm{X}}$. For conventional turbofan engines, $\mathrm{LTO} \mathrm{NO}_{\mathrm{X}}$

\footnotetext{
*The propulsor diameter is a key design variable in determining how much of the upper fuselage boundary layer is captured and ingested; thus the number of propulsors varies with their size.
}

4 of 22

American Institute of Aeronautics and Astronautics 
is measured on a static engine test stand, despite the regulations being cast in terms of an airplane operational cycle. Thus, the LTO $\mathrm{NO}_{\mathrm{x}}$ certification test is entirely independent of any airplane-related characteristic. The vehicle and propulsion system of the N3-X, however, are closely coupled and highly integrated. The turboshaft engines themselves produce very little thrust via their tailpipe exhausts, ${ }^{*}$ and thus by themselves should not be subject to emission regulations at all. But the propulsor fans - which create no exhaust emissions themselves but produce nearly all of the vehicle's thrust - cannot function without the turboshaft gas turbine engines!

The exhaust emissions of the N3-X would presumably be regulated by authorities in a manner yet to be determined. To be evaluated on a static engine test stand as ordinary turbofan engines are, the turboshaft engines would need to have a simulated mockup of the loads created by the balance of the electric propulsion system. Perhaps thrust performance and emissions would need to be measured separately at different facilities rather than at the same time. Other hybrid-electric concepts may have similar certification dilemmas in the future.

For the purposes of this LTO $\mathrm{NO}_{\mathrm{X}}$ emissions assessment, it is assumed that the total $\mathrm{NO}_{\mathrm{X}}$ emitted over the operational cycle $\left(D_{p}\right)$ is the $\mathrm{NO}_{\mathrm{X}}$ produced by both turboshaft engines; while the sea level static rated thrust $\left(F_{o o}\right)$ is the total airplane thrust produced by all twelve of the propulsor fans and the two turboshaft tailpipe jets.

Empirical correlation models are often used in conceptual design studies to predict an engine's $\mathrm{NO}_{\mathrm{X}}$ emission index $\left(E I N O_{X}\right.$, defined as masses of $\mathrm{NO}_{\mathrm{X}}$ emitted per thousand masses of fuel burned). Correlations for $E I N O_{X}$ are typically developed using emissions data collected from combustor rigs or flame tube experiments. Predictions for $D_{p}$ are made by multiplying the correlated $E I N O_{X}$ values by the predicted fuel flow rates and the durations for each of the four operational modes. In this study, a correlation model developed during NASA's Ultra-Efficient Engine Technology Project is used to predict $E I N O_{X}$ :

$$
E I N O_{X}=a_{0} p_{3}^{a_{1}} \exp \left(T_{3} / a_{2}\right) f_{\text {local }}^{a_{3}}
$$

The model is a strong function of the combustor mixing zone average reaction temperature, represented in the correlation by the localized fuel-air mass ratio in the combustion zone, $f_{\text {local }}$. Thermodynamic cycle analysis codes like NPSS, however, typically track the overall fuel-air ratio, $f_{\text {overall }}$ (i.e., the ratio of the fuel and air flow rates entering the combustor) rather than $f_{\text {local }}$, and use a value supplied by the analyst for the amount of combustor liner cooling dilution air. In this simple model, $f_{\text {local }}$ is approximated by $f_{\text {overall }} /(1-C)$, where $C$ is the fraction of combustor liner cooling air diverted around the combustor snout. Higher amounts of cooling air make the localized burning zone richer. For this analysis, the cooling air fraction is set to only 10 percent, since the combustor liner is assumed to be made from high-temperature ceramic matrix composite material that would require less cooling than a conventional liner. The exponent $a_{3}$ is assumed to be 2.4 .

Significant increases in NO have been observed to be a function of combustor entrance temperature ${ }^{19}$ and, to a lesser extent, combustor entrance pressure ${ }^{20,21}$. Therefore, the correlation is also a function of combustor entrance total temperature $T_{3}$ and total pressure $p_{3}$. NPSS computes and tracks both of these properties. With $p_{3}$ and $T_{3}$ in units of psia and ${ }^{\circ} \mathrm{F}^{\dagger}$, the constants $a_{1}$ and $a_{2}$ are 0.35 and 300 , respectively.

The constant $a_{0}$ in the correlation model represents a combustor emissions technology level and is set to 122 for low-emission combustor performance expected by the N+3 timeframe. To duplicate the test conditions required by emissions certification regulations, NPSS computes engine data at sea level, static, standard day (ISA) conditions, and with an inlet pressure recovery set to unity to simulate an engine test stand inlet control device. Regulations permit customer power extraction and customer bleed to be turned off during testing. However, the N3-X is assumed to operate with an electric systems architecture without customer bleed, and any customer power requirement is derived from the electrical system.

\section{B. Slot Nozzle Jet Noise Analysis}

The fan propulsors exhaust through an array of convergent slot (rectangular) nozzles at or near the trailing edge of the wingbody planform as shown in Figure 2. As discussed in the introduction, the N3-X configuration using vectorable slot nozzles with exit planes at the planform trailing edge was proposed because of the known jet noise penalty associated with jet noise scrubbing over a horizontal pitch effector. This penalty is shown graphically in Figure 8 of Bridges' paper (Ref. 12) for beveled nozzles with unheated jets at subcritical pressure ratios. Referring to the figure, a large bevel (representing a long pitch effector) increases jet noise by about $0.5 \mathrm{~dB}$ over a range of azimuth angles for nozzles with aspect ratio $A R$ of 2 . But if $A R$ is larger (8), then the bevel increases noise by about

\footnotetext{
*Most of the turboshaft core stream enthalpy is used to drive the power turbine, resulting in a low-energy exhaust.

${ }^{\dagger}$ Usually a ratio of two Fahrenheit temperatures is not sensible, but the correlation is a fit of data and is accurate within its range.

5 of 22

American Institute of Aeronautics and Astronautics
} 
$2 \mathrm{~dB}$ for centerline observers (i.e., underneath the nozzle), but only by perhaps $0.5 \mathrm{~dB}$ broadside. The scale model slot nozzle design space investigated by Bridges is shown in Figure 4.

The initial airplane configuration shown in Figure 2 (top), of course has no bevel jet noise penalty. However, once the noise analysis was performed on this initial configuration, it became clear that fan discharge noise was higher than the slot nozzle jet noise. Thus, for the low-noise configuration shown in Figure 2 (bottom), the bevel nozzle jet noise penalty was accepted in order to use the pitch effector to provide additional shielding for the fan discharge noise. For the low-noise configuration, $0.5 \mathrm{~dB}$ is added to the slot jet source at the lateral condition, and $1.5 \mathrm{~dB}$ is added to the source at the flyover and approach condition. This simple system-level correction is based on an examination of the unheated, subcritical, shock-free data for beveled nozzles in Ref. 12. The details regarding this selection are below.

In any case, an analytical model for predicting jet noise of slot nozzles is needed to complete this part of the task. The preferred method for predicting jet noise within ANOPP is via the Stone jet noise module, ST2JET. ${ }^{22}$ ST2JET has been shown to predict jet noise of a variety of axisymmetric nozzles very well, ${ }^{23,24}$ but it is not currently capable of predicting the jet noise of rectangular nozzles. It is preferable to modify and extend the approach used in ST2JET to slot nozzles rather than develop an entirely new method for this task. The modifications to ST2JET are described in the following paragraphs.
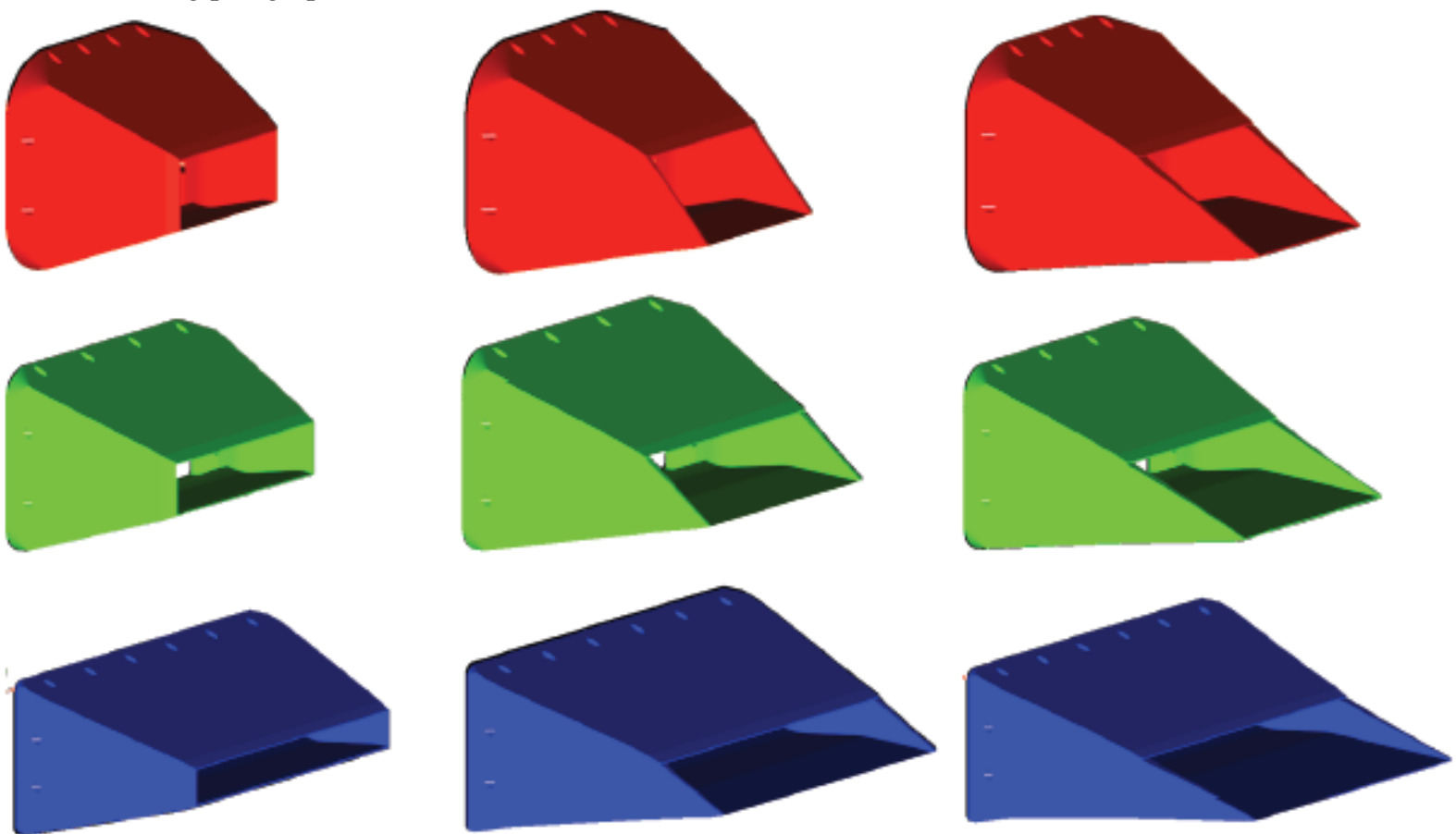

Figure 4. Slot nozzle geometry design space (varying with nozzle $A R$ and bevel length) from Ref. 12 (Graphic: NASA/Bridges).

Stone approaches the jet noise problem by breaking the overall jet noise into several virtual components, each accounting for different noise-generation mechanisms within the jet plume. Stone empirically models four turbulent mixing noise components and three shock-related noise components. But since the N3-X fan propulsors operate at very low pressure ratios, the slot nozzle jets are always subcritical and shock-free. Thus, the ST2JET shock noise components are not used and no modifications are proposed for them.

Of the four virtual turbulent mixing noise components, one component accounts for the high-frequency noise resulting from flow separation along a nozzle plug centerbody. But since the N3-X slot nozzles have no centerbodies, no attempt is made to extend the prediction for this component to rectangular exits.

The three remaining jet noise components are 1) the large-scale, merged-stream mixing noise (low-frequency content generated by the large turbulent eddies several diameters downstream of the exit plane), 2) the small-scale mixing noise (relatively high-frequency content generated at the exit plane of the nozzle by the jet-to-ambient shear layer), and 3) the transitional, intermediate-scale mixing noise. The intermediate-scale noise is the most difficult component to characterize. It is predominantly caused by the inner shear layer at the interface between the streams 
of a coannular nozzle. Stone, however, proposes that it is present in single-stream nozzles as well (like the N3-X), where it is required to completely correlate the measured data.

Stone's empirical relations for these three remaining mixing noise components are extended to rectangular slot nozzles. Several simple modifications are proposed below and the resulting framework is calibrated using unheated, subcritical, shock-free data from Ref. 12. The proposed method is intended to be applicable to single-stream slot nozzles with no centerbodies and with subcritical, unheated flow. Further development will be necessary to extend Stone's method to more complex flows and geometries.

The geometry of a convergent slot nozzle with exit dimensions of width $W$ and height $H$ is shown in Figure 5. The coordinate origin is the center of the nozzle exit plane. The ANOPP convention for azimuthal (roll) angle $\phi$ is used, such that ninety degrees is broadside and zero is nadir. $\phi_{\text {corner }}$ is the azimuthal angle when $\phi=\arctan (A R)$. From historical experience, the maximum jet noise of a slot nozzle occurs at $\phi=0$. A function is desired that accounts for the change in jet noise level with $\phi$ for a given $A R$. The noise reduction due to aspect ratio for $\phi>\phi_{\text {corner }}$ is hypothesized to be related to the ratio of the distance from the origin to the nozzle edge (i.e., $W / \sin \phi$ ) to the length for $\phi=0$ (i.e., $H$ ). Further, the noise reduction is required to fall off to a zero effect at $\phi=0$. A geometry factor $G$ is defined after a suggestion by James R. Stone ${ }^{*}$

$$
G(A R, \phi)= \begin{cases}\frac{1}{\cos \phi}, & \phi<\phi_{\text {corner }} \\ \frac{A R}{\sin \phi}, & \phi>\phi_{\text {corner }}\end{cases}
$$

The logarithm of $G$, plotted in Figure 6, is the basis of the empirical calibration. The sound pressure levels measured from the unheated subcritical jets of Ref. 12 are adjusted for spherical spreading, ambient source strength, and jet density; thus correcting the levels for everything save exhaust velocity, aspect ratio and viewing angles. The trends are examined and a polar angle-, azimuth angle-, and aspect ratio-dependent empirical adjustment term $F$ is proposed to account for rectangular exit effects on the overall level

$$
F= \begin{cases}0, & \theta<90^{\circ} \\ 3\left[\left(\theta-90^{\circ}\right) / 60^{\circ}\right] \log _{10} G(A R, \phi), & \theta>90^{\circ}\end{cases}
$$

where $\theta$ is the polar (yaw) angle, with the zero reference at the nose of the airplane. $F$ (always positive, in decibels) is subtracted from the mixing noise levels predicted in ST2JET. Only small changes in levels are observed for polar angles less than ninety degrees, thus $F=0$ in the forward quadrant. The quietest zone (relative to an equivalent round nozzle) is directly broadside the nozzle (i.e., viewing the short side), particularly in the aft quadrant.

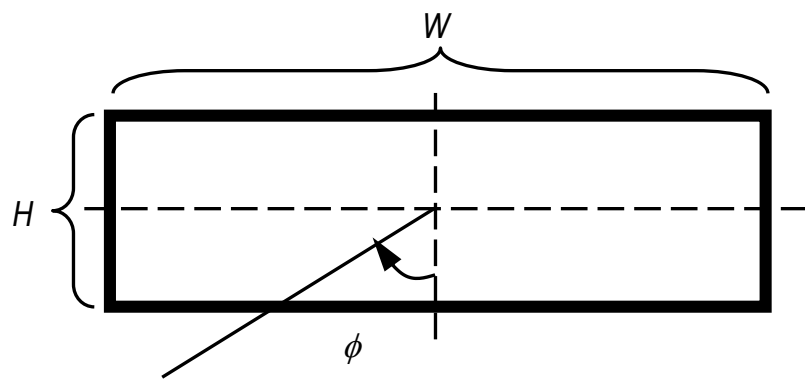

Figure 5. Slot nozzle dimensions.

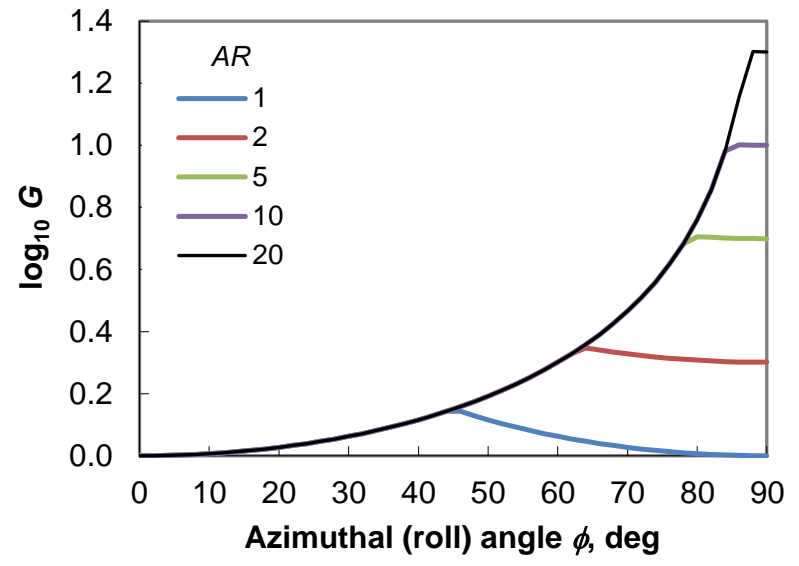

Figure 6. Slot nozzle geometry factor.

\footnotetext{
*Stone always intended to extend his axisymmetric ST2JET model to rectangular jets, but lacked the time and resources. The approach that follows is believed similar to the path Stone may have taken.
}

7 of 22

American Institute of Aeronautics and Astronautics 
The overall jet noise level is modified by the new $F$ term for azimuthal (roll) angles $\phi>0$. Therefore, only observers on a lateral sideline are affected by these changes proposed to the ST2JET model. However, there is an aspect-ratio-related spectral shift towards higher frequencies that adversely impacts psychoacoustic noise metrics (such as the perceived noise level weighting used in certification). So even observers along the runway centerline where $\phi=0$, such as the approach and flyover monitors, are affected slightly by rectangular exit geometry.

The spectral shifting may be accounted for by a modification to the jet Strouhal number. The SAE recommends ${ }^{25}$ an additional diameter ratio term $\left(d_{\text {hyd }} / d_{\text {ideal }}\right)^{0.4}$ to be multiplied into the Strouhal number:

$$
S t=\frac{f d_{\text {eff }}}{V_{\text {eff }}}\left(\frac{d_{\text {hyd }}}{d_{\text {ideal }}}\right)^{0.4}\left(\frac{T}{T_{\text {amb }}}\right)^{0.4(1+\cos \theta)}
$$

where the ideal nozzle diameter $d_{\text {ideal }}$ is the equivalent round diameter of the ideally-expanded, fully-merged stream, [ $\left.4 H W\left(A / A_{t h}\right) / \pi\right]^{0.5}$. The term $A / A_{t h}$ is the isentropic area expansion ratio: a function of $M_{\text {ideal }}$ and the specific heat ratio. It has a value of unity for subcritical nozzles having $M_{\text {ideal }} \leq 1$, and a value greater than unity for supercritical nozzles with $M_{\text {ideal }}>1$. The hydraulic nozzle exit diameter $d_{\text {hyd }}$, simplified for a rectangular slot, is $2 H W /(H+W)$. The other terms in the Strouhal number relation are Stone's terms for effective diameter, effective velocity, total temperature and frequency (See Ref. 22). The characteristic frequencies of the slotted nozzle turbulent mixing noise components increase by the inverse of the factor $\left(d_{i d e a l} / d_{h y d}\right)^{0.4}$. For subcritical convergent slotted nozzles, this frequency multiplier is a function of $A R$ only and is plotted in Figure 7 against $A R$.

Some discussion of what value of $A R$ to use for each of the three jet mixing noise components is warranted for this application. The long N3-X slot nozzle that spans much of the wingbody trailing edge is actually an array of twelve individual slot nozzles for each of the twelve propulsor fans. Vertical walls separate the flows from each other up to the nozzle exit plane, although the streams would inevitably mix somewhat downstream in the ambient air. The $A R$ for the each of the smaller slots is less than 2, but the $A R$ for the entire array of slots is more than 20. In such an arrangement, one might expect the three mixing noise components to react to different values of $A R$. The large-scale jet mixing noise generated by large turbulent eddies several diameters downstream of the exit plane may react to

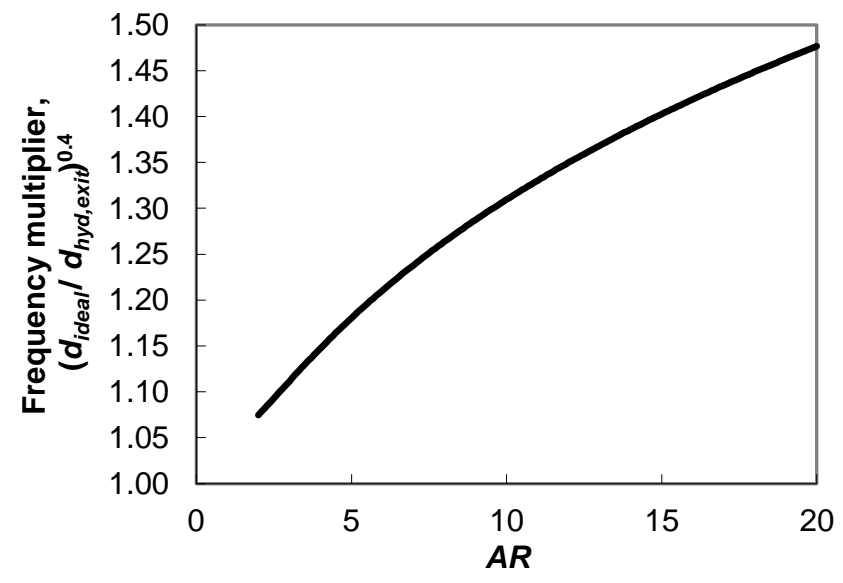

Figure 7. Mixing noise frequency shift due to aspect ratio for subcritical convergent slot nozzles. an $A R$ closer to 20. But the small-scale mixing noise is generated by the shear layer near the nozzle exit plane and may react to the $A R$ of the smaller slot, with the intermediate-scale component falling somewhere between. In this study, $A R$ values of 2, 10, and 20 are assigned to Stone's small-, intermediate-, and large-scale mixing noise components.

For the thrust-vectoring N3-X configuration (Figure 2, top) the effect of the thrust vectoring mechanism on the slot nozzle jet noise is not considered. Finally, the $1 / 3^{\text {rd }}$ octave band jet noise spectra are computed outside of ANOPP in a stand-alone version of ST2JET modified for slot nozzles as described above. These spectra are fed into ANOPP via its Acoustics Data Module $\left(\mathrm{ACD}^{26}\right)$. ACD is an ANOPP utility that allows user-supplied spectra to be fed into a certification simulation in lieu of using ANOPP's own, built-in, source noise prediction modules.

\section{Propulsor Fan Noise Analysis}

A method is required to predict the noise generated by the twelve fan propulsors. In ANOPP, fan noise is usually evaluated by predicting the noise of fans absent any acoustic treatment (a suppression spectrum due to treatment is typically applied afterwards) by one of ANOPP's built-in hardwall fan noise prediction modules. A logical choice may seem to be the method developed for large fans by General Electric. ${ }^{27} \mathrm{GE}$ 's method consists of a recalibration of the original fan noise method developed for ANOPP by Heidmann. ${ }^{28}$ While the overall structure of Heidmann's original empirical method remained intact, GE adjusted the method's numerical constants to predict fan noise at levels that reflected GE's experience base with large turbofans in service just prior to 1996: the CF6-80C2, CFM56,

8 of 22

American Institute of Aeronautics and Astronautics 
E3, and QCSEE engines (see Ref. 27 for details). These engines have fans with relatively narrow chords, straight blades, and high pressure ratios; whereas modern fans are designed with wider chords, swept and contoured blades, and, like those used in the N3-X, often have lower pressure ratios and tip speeds.

In this study, an undocumented recalibration of the Heidmann fan noise method is used. In 2006, acoustic investigators employed by Diversitech, Inc., working under contract with NASA, obtained several scale model fan acoustic datasets collected from the NASA Glenn 9- by 15-foot Low Speed Wind Tunnel. Of particular importance were the datasets collected from scale model representations of the CF6-80E1 fan and the Advanced Ducted Propulsor fan. ${ }^{29}$ The former dataset is significant because the fan was equipped and tested with several stator sets that allowed investigations into stator sweep and lean technology. The latter dataset is significant due to its unique operation in very low fan pressure ratio regimes. It provided insight into the noise generation mechanisms of these types of fans without the masking influence of shock-related sources found in other fans with tips operating in supersonic regimes. The fan noise prediction method based on these advanced fan designs is used in this assessment since it is more representative of modern, contoured, wide-chord fans for high bypass ratio turbofans. This method was coded and used with the other ANOPP source noise prediction methods.

The N3-X inlet and exhaust duct configuration is very unconventional. The inlet is a curved duct that entrains boundary layer flow and is partially submerged in the wingbody (see Figure 8). The inlet transitions from rectangular at the inlet highlight to round at the fan face, and from round to rectangular again at the slot nozzle exit. The fan noise prediction method described above is calibrated using acoustic data of fans operating in a

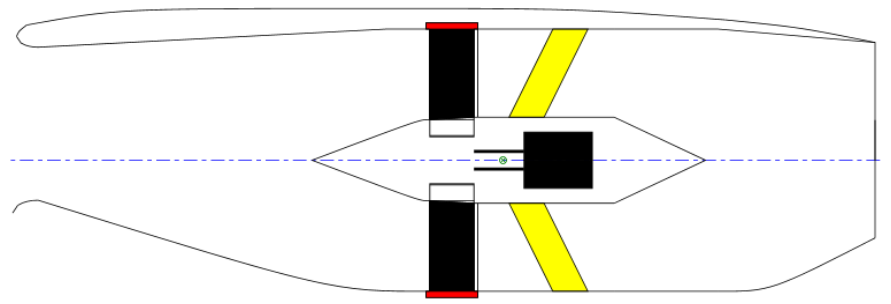

Figure 8. Sketch of a fan propulsor and its flowpath. conventional axisymmetric inlet and nozzle turbofan engine system. A fan operating in a duct system like the one shown in the figure should have much different radiating characteristics than those predicted by the revised Heidmann method. Without additional analysis or test data outside the scope of this study, the prediction error is unknown.

Acoustic treatment is assumed to line much of the interior of these long, complex ducts. Accurately predicting the acoustic treatment suppression spectra is difficult enough for conventional axisymmetric systems, much less for the duct system sketched in Figure 8. An empirical ANOPP treatment model developed by General Electric ${ }^{30}$ is used to predict the N3-X liner performance. The method predicts liner suppression spectra based on gross duct geometry inputs such as length and diameter, and the suppression spectra are subtracted from the hardwall fan noise spectra. But the method is inaccurate by an unknown amount since it is calibrated to liner performance of conventional turbofans with round inlets and annular discharge ducts. Additional analysis using higher-order duct acoustic and liner suppression codes is needed to more accurately predict the N3-X fan noise, but that task lies outside the scope of this initial study.

In any case, the relatively long duct lengths should (and do) result in good fan suppression levels using the GE treatment model. The aft duct liner suppresses fan discharge noise by about $6 \mathrm{~dB}$ at frequencies around $4 \mathrm{kHz}$. However, applying acoustic treatment to the interior corners where the aft duct transitions to rectangular may be difficult and may result in ineffective performance. The inlet attenuation is much higher. Using an estimated inlet axial length of 80in, the effective length-to-fan-diameter ratio is 1.4: about three times that of a conventional turbofan inlet. Peak inlet suppression is predicted to be more than $30 \mathrm{~dB}$ at frequencies around $4 \mathrm{kHz}$. That suppression would be put to good use. Unlike a conventional wing-mounted turbofan enjoying freestream air, the flow entering the N3-X fans is distorted and would result in an increase in rotor-stator interaction tones. But the inlet flow distortion typically increases only the inlet-radiated fan noise. With the very effective inlet treatment and with so much forward shielding provided by the wingbody planform, the distortion noise penalty should be a minor concern.

\section{Turboshaft Engine Noise Analysis}

Combustion, turbine, and compressor noise are often collectively known as core noise. While creating electrical power for the N3-X, the two turboshaft engines create core noise as well as some jet noise from their tailpipe exhausts. In the first N3-X configuration evaluated (Figure 2, top), the turboshaft engines are mounted on the wingtips. With these engines fully exposed to observers on the ground, accurate core noise modeling is essential.

It is envisioned that the electric generator would be located forward of the turboshaft engine's compressors and enclosed in an inlet centerbody (see Figure 9). It would be driven by a central shaft connected to the third spool

9 of 22

American Institute of Aeronautics and Astronautics 
power turbine at the aft end of the turboshaft engine so that it could avoid the high temperatures of the hot section. If the inlet is long in order to accommodate the generator, there may be enough internal surface area to apply treatment and bring any forward-radiated compressor noise under control. But combustor and turbine noise are predominantly aft-radiated and propagate through a short, plugged tailpipe. These noise sources will be difficult to reduce. High shaft speeds, high blade counts and cutoff designs should help reduce turbine noise levels. And the presence of the power turbine has an important core noise attenuating effect, as discussed below.

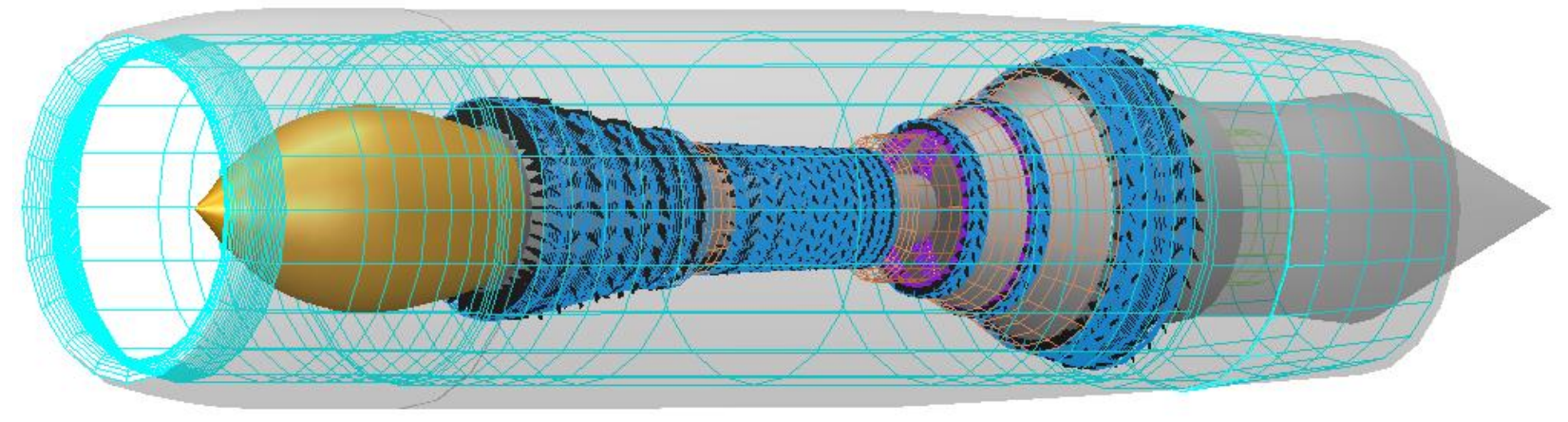

Figure 9. Solid model of a three-spool turboshaft electric generator.

Historically in noise certification of conventional turbofan airplanes, core noise has tended to be significant only at the approach certification point. Core noise is sometimes revealed at low, approach throttle settings when fan and jet noise are reduced due to lower fan tip speeds and lower nozzle exhaust velocities. A fundamental turbine discrete interaction tone may also fall under $10 \mathrm{kHz}$ at approach throttle and may become an issue. In advanced turbofan engines, however, core noise may become significant at higher throttle settings as well, since jet and fan noise are lower due to increased bypass ratio, low fan tip speeds, and modern, more effective noise reduction technologies. As jet and fan noise sources are reduced via engine cycle design changes and noise reduction technologies, core noise becomes "uncovered" and increasingly problematic. Moreover, core noise continues to rise as engine makers seek ever-higher core pressures, blade loadings, and hot-section temperatures.

For the N3-X turboshaft engines, core noise is predicted using ANOPP's built-in procedure (the GECOR module) developed by Emmerling ${ }^{31}$ and later modified by Ho. ${ }^{32}$ Results from NASA's acoustic tool benchmarking study $^{33}$ indicate that the ANOPP method agrees well with static core noise separated from the overall acoustic signature of the Honeywell TECH977 business-jet-class research engine. ${ }^{24}$ General Electric also evaluated the ANOPP core noise method favorably in 1996 based on static acoustic test comparisons to CF6-80C2, QCSEE, and E3 engines, as well as comparisons with their own proprietary method. ${ }^{27}$

But two key differences between the engines used for the GECOR method's validation and the N3-X turboshafts are cause for concern. The first is the high core pressure at which the N3-X turboshafts operate. A key input to the prediction method is the maximum cycle pressure. The N3-X overall pressure ratio is 59 at the lateral sideline condition (because of the cycle lapse, it is higher still at top of climb). Beginning with ANOPP Level 30, the maximum overall pressure ratio allowed in GECOR was raised to 60 (it had been 30, since the engines to which it is calibrated date from the 1970s), but there are as yet no data to support it. In other words, the prediction method is extended beyond its validation range. The overall sound pressure levels increase with $20 \log _{10}(\mathrm{OPR})$ (in decibels, where OPR is the engine overall pressure ratio), so extrapolation beyond the data may not be unreasonable. In any case, additional core noise data taken at high pressures are needed to validate the method for high pressure ratio engines.

The second difference is that GECOR is calibrated against turbofans rather than turboshaft engines. Core noise is primarily composed of direct and indirect combustion noise, with the turbine(s) considerably influencing the noise level that propagates to the far field. In a turboshaft engine where a power turbine extracts a great deal of enthalpy from the core flow (e.g., as in the N3-X), the core noise is significantly reduced and an accurate turbine attenuation transfer function is required. Following a suggestion by Hultgren, ${ }^{34}$ the overall level is adjusted by $10 \log _{10}\left[0.8 \zeta /(1+\zeta)^{2}\right]$, in decibels, where $\zeta$ is the acoustic impedance ratio across all three turbines (i.e., the product of the density and sound speed at the power turbine exit divided by the density and sound speed at the high-pressure turbine entrance). Beginning with ANOPP Level 30v3, this version of attenuation factor has become a permanent feature of GECOR. This method of accounting for the power turbine attenuation will be used until the model is calibrated with actual turboshaft engine data.

10 of 22

American Institute of Aeronautics and Astronautics 
For the version of the N3-X where the turboshaft engines are exposed to ground observers (Figure 2, top), it is assumed that bulk absorption liners effective at suppressing broadband core noise (at "non-targeted" frequencies) are present in the inlet and exhaust ducts. The bulk material and perforated face sheet covers would need to withstand the high temperatures of the exhaust. Although there is little experience to date with such liners in turboshaft engines, it is assumed that they may find their way onto engine cores by the N+3 timeframe. ANOPP's acoustic treatment prediction module (discussed in the previous section) is based on an empirical calibration of single- and double-degree-of-freedom perforated liners bonded to honeycomb cavities rather than bulk absorption material. Nevertheless this method is applied to the problem as an interim approach until a better analysis can be performed.

The turboshaft engine exhausts through a conventional, single-stream, axisymmetric, convergent tailpipe with a centerbody plug. The resulting jet noise is modeled using ANOPP's ST2JET (discussed earlier). Following passage through the power turbine, enthalpy is effectively removed, and the tailpipe exhaust velocity is very low. The tailpipe jet exit velocity is quite subsonic - and relatively quiet - even at maximum throttle.

\section{E. Airframe Noise Analysis}

Airframe noise sources for conventional aircraft ordinarily tend to be significant only during approach, when engine throttle settings are reduced. For the N3-X and its effectively-shielded propulsor fans, however, airframe noise sources may be expected to be noticeable not only on approach but at higher throttle settings as well, since they may become audible over the already-low fan and jet noise sources. In addition, for practical reasons and safety considerations, air traffic on approach tends to fly over significant distances at comparatively low altitude. This is in sharp contrast to departure trajectories, where the pilot's intent is to gain altitude rather quickly. Remarkably, despite having much louder noise signatures on departure than on approach, this behavior results in noise "footprints" that have roughly equivalent enclosed areas on approach and departure. Accurate airframe noise modeling methods are therefore required for the N3-X. Specifically, noise prediction methods are required for the landing gear, planform surface trailing edges, and high-lift devices.

Landing gear noise is predicted using an ANOPP method developed by Guo at Boeing. ${ }^{35,36}$ The method has been validated favorably by NASA. ${ }^{37}$ Guo's method accepts general landing gear geometric inputs (such as tire and strut dimensions) and flight conditions corresponding to the trajectory (discussed in a later section), and computes spectra for the main and nose gear. Based on the flight Mach number input by the user, the method automatically computes a reduced local Mach number in the vicinity of the gear due to wing lifting effects. These adjustments are based on data for conventional tube-and-wing aircraft. However, several preliminary flowfield analyses indicate that there is no Mach number suppression on hybrid wingbody airplanes like the N3-X. Indeed, some studies have indicated it is somewhat higher than the freestream Mach number. Since there is no provision in ANOPP for the user to specify or adjust the local Mach number, the flight Mach number input is artificially increased so that the internally-computed local Mach number is equal to the flight Mach number. This modification only affects the predicted gear noise without impacting any other ANOPP module.

The main gear and nose gear are assumed to have spoilers for flow deflection and fairings to improve the aerodynamic shape while still allowing easy access for maintenance and inspection. These noise reduction technologies are anticipated to mature by the $\mathrm{N}+3$ timeframe. Representative gear noise suppression spectra taken from Ref. 38 are subtracted from the spectra predicted by Guo's method.

Planform trailing edge surface noise is predicted using a method developed by M.R. Fink in $1977^{39}$ using his option for delta-wing airplanes. The Fink method - programmed into ANOPP's FNKAFM module - accepts gross airframe dimensions that may be obtained from a simple three-view aircraft drawing. As the N3-X has no tail surfaces, the vertical and horizontal tail span and tail area inputs are set to the module minima so that empennage noise is excluded from the prediction. No noise reduction technologies are assumed for trailing edge surface noise.

Retractable high-lift devices also contribute to the airframe noise signature. The N3-X is envisioned to use no leading edge slats in the conventional sense. Instead, a leading edge "droop" is used on approach. Unlike conventional leading edge slotted slats, the "droop" uses no slot to keep the upper surface flow attached, and it relies only on camber effects to achieve high lift. Since flow through a slot is the principal slat noise source, the leading edge droop noise source is assumed low enough to be ignored in this analysis.

Trailing edge flaps are deployed on approach; and, to a lesser degree, on takeoff. For the first N3-X variant (shown in Figure 2, top), the trailing edge flap arrangement is assumed to consist of relatively conventional, inboard- and outboard-segmented, double-slotted flaps. The noise of these flaps are also predicted by the Fink method. No flap noise reduction technologies are assumed. Some hybrid wingbody studies have assumed a slotless flaperon-type elevon high-lift system. This kind of flap system is used for the alternative low-noise N3-X variant

11 of 22

American Institute of Aeronautics and Astronautics 
(shown in Figure 2, bottom). The noise of this type of slotless flap is assumed low enough to be ignored. Scrutiny of these portions of the Fink method to date has not yet revealed any fundamental issues. ${ }^{37}$

\section{F. Planform Area Shielding and Lateral Engine Clustering Model}

Noise shielding (also referred to as barrier attenuation or insertion loss) is an acoustic diffraction phenomenon where acoustic waves are attenuated when propagated past an impermeable barrier placed between the noise source and an observer. Shielding is particularly efficient when the observer is located in the "shadow region" where the noise source is obscured. The N3-X planform provides an effective shielding surface for the fan propulsors located atop the planform. Noise produced by the turboshaft engines for the low-noise variant (Figure 2, bottom) is also shielded. The airframe noise sources and the propulsor slot nozzle jet noise - a distributed source generated downstream throughout the axial exhaust plume - are not shielded.

The method used to predict shielding is a simple empirical diffraction model based on asymptotic results of optical diffraction theory, originally proposed by Maekawa ${ }^{40}$ and reproduced in many foundational acoustic textbooks (e.g., Ref. 41). The analytic treatment of diffraction effects in this manner is common in aeroacoustic applications. Being reliable, fast, and easy to implement, it has been coded into aircraft noise system prediction programs such as the General Aviation Synthesis Program ${ }^{42}$ in 1982 and later into ANOPP. ${ }^{43}$

Maekawa proposed the shadow zone barrier attenuation relation:

$$
L_{I}=20 \log _{10}\left(\sqrt{2 \pi\left|N_{F}\right|} / \tanh \sqrt{2 \pi\left|N_{F}\right|}\right)+5
$$

in $\mathrm{dB}$, where $N_{F}$ is the frequency-dependent Fresnel number $(2 f \Delta / c)$, whose characteristic length $\Delta$ is the difference between the shortest path around the barrier between the source and the observer and the source-observer distance directly through the barrier.

For observers in the bright zone $\left(N_{F}<-0.192\right)$, the attenuation is neglected, and for observers in the transition zone $\left(-0.192<N_{F}<0\right)$, it is appropriate to replace the hyperbolic tangent with the trigonometric tangent. Although the above relation is intended for use with semi-infinite barriers, Maekawa suggested that superposition may be used for barriers of finite length and width. This simple diffraction method is built into ANOPP's WING module.

A simple model not in ANOPP is proposed to account for the effects of engine clustering. An observer located directly broadside the N3-X (at $\phi=90^{\circ}$ ) should not perceive the noise of all twelve propulsor fans, while observers under the vehicle $(\phi=0)$ probably should. The effective number of engines perceived by an observer, $N_{E, \text { eff }}$, is proposed to be a linear, non-discrete function of $\phi$ :

$$
N_{E, \text { eff }}= \begin{cases}N_{E}, & \phi<45^{\circ} \\ 1+\left(N_{E}-1\right) \frac{90^{\circ}-\phi}{45^{\circ}}, & \phi>45^{\circ}\end{cases}
$$

Observers underneath the airplane (to an angle up to 45 degrees from nadir) perceive the total number of propulsor engines $N_{E}$, but $N_{E \text {,eff }}$ vanishes to unity at angles broadside to the airplane. This engine clustering effect influences the lateral noise monitor only.

\section{G. System Noise Modeling}

\section{Trajectory and monitor locations}

An important aspect of noise certification is the influence of trajectory and engine throttle settings on noise. As of this writing, there have been no calculations for a takeoff and approach trajectory for the N3-X. The highly coupled thrust and low-speed aerodynamics may make this a challenging task. In lieu of computing a trajectory, a surrogate trajectory of an aircraft similar to the $\mathrm{N} 3-\mathrm{X}$ is sought.

The Boeing N2B transport ${ }^{44}$ (from which, in part, the N3-X is derived) is a hybrid wingbody aircraft using planform-embedded propulsion, and with similar high-lift devices, gross weight, wing loading, and thrust loading as the N3-X. Since it is likely to have similar performance characteristics, its takeoff and approach trajectories are used for this study.

Boeing performed a traditional time-stepping trajectory analysis for a sea level field on a standard acoustic day $\left(\mathrm{ISA}+18^{\circ} \mathrm{F}\right)$ using the N2B vehicle's weight, low-speed aerodynamics and NASA's embedded engine thrust data. Compliance with the airworthiness requirements described in Parts 36 and 25 of the Federal Aviation Regulations (Refs. 10 and 45, respectively) is observed.

12 of 22

American Institute of Aeronautics and Astronautics 
At brake release, the transport's total rated static thrust is $149,000 \mathrm{lb}$. Flaps are set at the first detent and a slight leading edge droop is assumed. The takeoff proceeds as follows:

1. Brake release and ground run at maximum thrust

2. Rotate such that the liftoff speed is $110 \%$ of the minimum unstick velocity with all engines operating, or $105 \%$ with one engine inoperative

3. Climb to the $35 \mathrm{ft}$ obstacle at maximum thrust

4. Retract gear and climb at constant calibrated airspeed at maximum thrust

5. At $17,500 \mathrm{ft}$ from brake release, reduce thrust to the minimum allowed cutback value (such that the climb gradient is zero with one engine inoperative or four percent with all engines operating)

6. Climb at constant calibrated airspeed at cutback thrust

7. At 23,000ft from brake release, increase thrust to power-up level

8. Climb at constant calibrated airspeed at power-up thrust

9. At $3000 \mathrm{ft}$ above field elevation, accelerate to flap retraction speed, retract flaps and leading edge droop

10. Accelerate to $250 \mathrm{ktcas}$ until $10,000 \mathrm{ft}$ above field elevation

The approach trajectory is calculated for a 3-degree glide slope at the maximum landing weight, with full flaps and full leading edge droop, and with gear down.

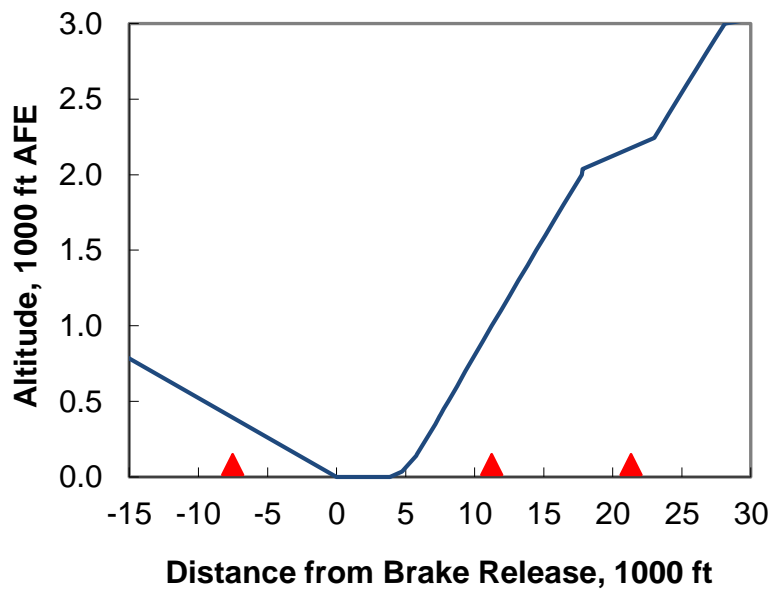

Figure 10. Altitude above field elevation.

Trajectory data for altitude, airspeed, and total net thrust are shown in Figure 10 through Figure 12, respectively. The trajectories shown are presented as a single operation with both takeoff and landing shown simultaneously. For presentation purposes, the touchdown point on landing is coincident with the point of brake release on takeoff. The triangular markers on each plot denote the three noise certification measurement locations. Note that in the interest of international rulemaking terminology harmonization, the former "sideline" certification monitor term has been deprecated in favor of "lateral," as has "takeoff" to "flyover." The noise certification observer arrangement is sketched in Figure 13.

The approach microphone markers are shown in the figures at $6562 \mathrm{ft}(2000 \mathrm{~m})$ behind the runway threshold (i.e., behind the location of the 50ft landing obstacle), and $7518 \mathrm{ft}$ from the touchdown point on the extended runway centerline. The airplane is at an altitude of $394 \mathrm{ft}(120 \mathrm{~m})$ as it passes over this location.

The lateral microphone markers are shown in the figures at $11,700 \mathrm{ft}$ from brake release, on a lateral sideline displacement distance of $1476 \mathrm{ft}(450 \mathrm{~m})$ from the runway centerline. The $11,700 \mathrm{ft}$ location is where the peak Effective Perceived Noise Level (EPNL) occurs along the sideline. The altitude of the N3-X at this location is 850ft

13 of 22

American Institute of Aeronautics and Astronautics 
above field elevation. At this altitude, the EPNL has peaked because lateral attenuation effects due to the ground have diminished but the airplane has not yet climbed high enough for spherical spreading to reduce its noise.

The flyover microphone markers are positioned $21,325 \mathrm{ft}(6500 \mathrm{~m})$ from brake release on the extended runway centerline. The noise abatement throttle cutback can be seen in Figure 12. The engine climb thrust at this point is reduced to the minimum level permitted by regulation. The throttle cutback takes place between $17,000 \mathrm{ft}$ and $18,000 \mathrm{ft}$ from brake release, where the N3-X is approximately $2100 \mathrm{ft}$ above the field. This is above the minimum altitude permitted (i.e., $984 \mathrm{ft}$, or $300 \mathrm{~m}$ for a twinjet), in an attempt to gain additional altitude over the flyover monitor. Compared to conventional aircraft, this altitude is approximately as high as a 737-class single-aisle airplane flies over the monitor. ${ }^{46}$

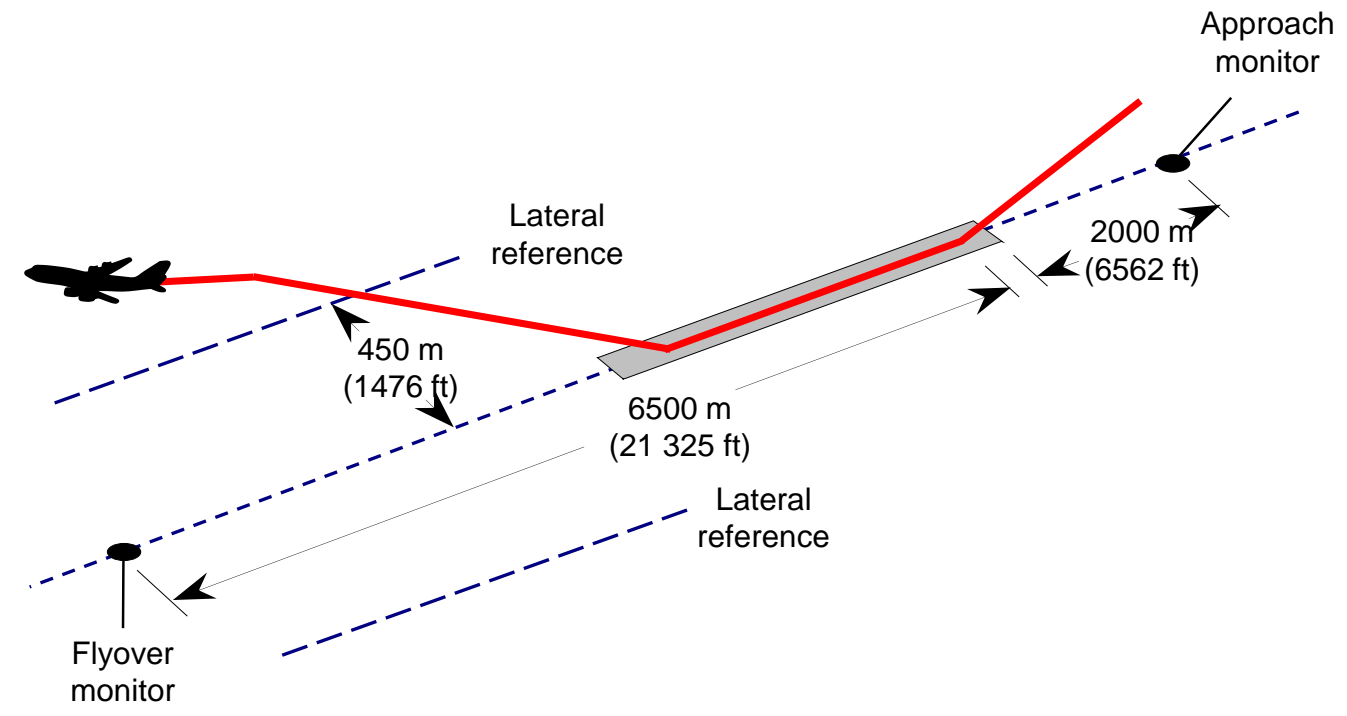

Figure 13. Noise certification observer arrangement.

\section{Propagation and certification noise calculations}

Using an assumption of acoustic superposition, the freefield, lossless spectra for all of the predicted noise sources are analytically summed in the vicinity of the aircraft. Of course in reality, noise sources are complex distributed signals that are affected by other acoustic sources, aircraft external surfaces, and the environment. With the exception of the shielding-diffraction effects described earlier in Section II.F, no provisions are made to adjust the component spectra for acoustic near-field phenomena such as source interactions, reflections, refraction, or other effects.

The summed spectra are propagated to the three certification monitors on the ground in accordance to the specifications for certification measurements. Considered noise propagation effects include spherical spreading, Doppler shift and convective amplification, atmospheric attenuation, ${ }^{47}$ ground reflections ${ }^{48,49}$ based on data for grass-covered ground, ${ }^{50}$ and extra ground attenuation. ${ }^{51}$ More complex propagation phenomena such as scattering, weather effects, and terrain are not modeled.

The airplane trajectory is fed into the ANOPP simulation. Vector geometry analyses for the airplane relative to the three certification microphone measurement locations - shown in Figure 13 - are performed within ANOPP as functions of source time. The propagated acoustic spectra are predicted at half-second intervals at each of the three certification locations. From these spectra, ANOPP computes several noise metrics of interest as functions of observer time. The EPNL certification noise metric is computed from the noise vs. time history at each observer as prescribed in Ref. 11.

\section{Results and Discussion}

\section{A. Emissions Results}

$\mathrm{NO}_{\mathrm{X}}$ emissions for the $\mathrm{N} 3-\mathrm{X}$ are predicted using data from the turboshaft engine model as described in Section II.A. The LTO $\mathrm{NO}_{\mathrm{X}} D_{p} / F_{\text {oo }}$ metric is estimated to be $17.6 \mathrm{~g} / \mathrm{kN}$ for the simulated idealized landing and takeoff cycle. This characteristic $\mathrm{NO}_{\mathrm{X}}$ is plotted against engine rated sea level overall pressure ratio in Figure 14. Also plotted in the figure are five regulatory emission standards for subsonic engines having rated sea level thrust greater than $89 \mathrm{kN}(20,000 \mathrm{lb})$. The FAA and the EPA have adopted the "tier" naming convention for aircraft engine

14 of 22

American Institute of Aeronautics and Astronautics 
emission regulations (Refs. 8 and 52, respectively). The tier numbers refer to levels of increased $\mathrm{NO}_{\mathrm{X}}$ emissions stringency levels and correspond to the ICAO CAEP meeting number naming convention. The standards range from the original Committee on Aircraft Engine Emissions (CAEE) limit to the newest Tier 8-CAEP/8 standard (at the time of this writing anticipated to go into effect in 2014). The NASA Fixed Wing Project's N+3 LTO $\mathrm{NO}_{\mathrm{X}}$ goal (80 percent less than the Tier 6-CAEP/6 standard) is also shown. The symbols in the figure are the levels of inproduction certificated subsonic engines with rated output greater than $89 \mathrm{kN}$ that are listed in the ICAO Aircraft Engine Emissions Databank. ${ }^{53}$ They are classified by date of manufacture of their first production model.

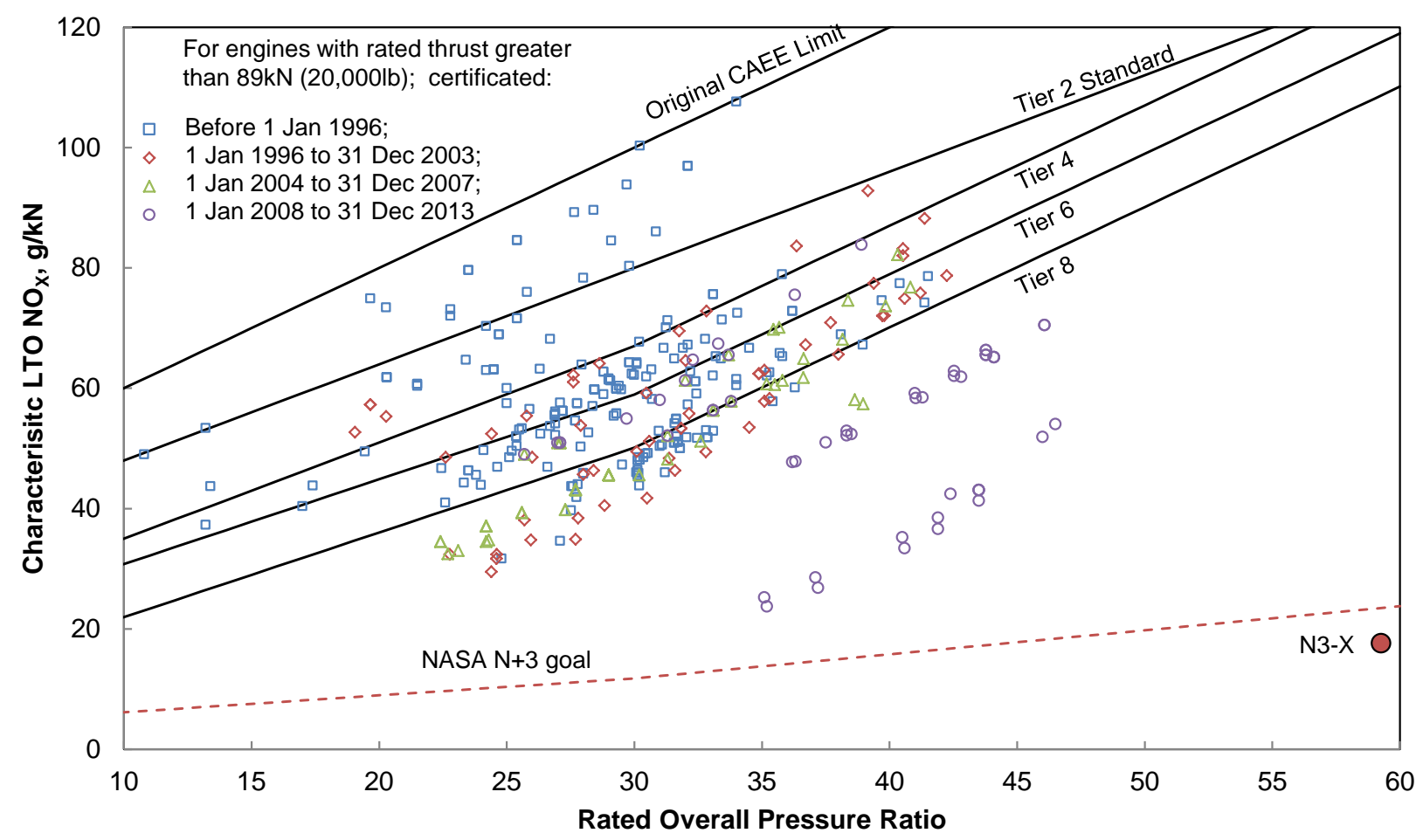

Figure 14. N3-X LTO $\mathrm{NO}_{\mathrm{x}}$ prediction relative to ICAO emission standards and data for certificated subsonic engines with rated thrust greater than $89 \mathrm{kN}$.

As noted in Section II, the N3-X would be something of a regulatory oddity. It is assumed that $F_{o o}$ is the static thrust of the entire vehicle, while $D_{p}$ is the mass of $\mathrm{NO}_{\mathrm{X}}$ produced by both turboshaft engines. Since the propulsion system and the vehicle are so tightly coupled, performing an emissions test on the N3-X may be more difficult than for conventional turbofans, where emissions are measured on an isolated engine test stand.

The N3-X turboshaft has an extremely aggressive overall pressure ratio. It is 59 at sea level, and it is higher still at top of climb because of the engine cycle's lapse with altitude. Designing advanced, low- $\mathrm{NO}_{\mathrm{X}}$ combustors would be challenging at such high combustor pressures. The correlation used in this study to predict $\mathrm{NO}_{\mathrm{X}}$ emission indices is based on data taken at much lower pressures. Applied to the N3-X, the simple correlation is extended beyond its verified range. Emissions data should be taken at much higher pressure to validate the correlation in that range.

With these assumptions, the N3-X emissions are estimated to be 85 percent less than the Tier 6-CAEP/6 standard. This is much lower than any in-production engine to date. It is lower even than the recently-certificated GEnx series with advanced Twin Annular Premixing Swirler combustors (the lowest of any current production turbofan). This exceeds NASA's N+3 environmental goal for local air quality.

\section{B. Certification Noise Results}

\section{Engine State Data}

Altitude, airspeed and throttle setting are noted from the N3-X trajectory as it passes each noise certification monitor location. These critical flight conditions are used to determine engine and aircraft state information. Engine state data are computed using the NPSS engine simulation at these flight conditions for a standard acoustic day $\left(\mathrm{ISA}+18^{\circ} \mathrm{F}\right)$. The engine state data are presented in Table 1. Flight Mach number, altitude, and power code (PC) corresponding to each of the three flight conditions (lateral, flyover, and approach) are shown. The engine data are

15 of 22

American Institute of Aeronautics and Astronautics 
Table 1. Propulsion data necessary for noise predictions at critical flight conditions.

\begin{tabular}{|c|c|c|c|c|}
\hline & $\begin{array}{c}\text { Lateral Condition } \\
\text { M0.221/1000ft PC50 }\end{array}$ & $\begin{array}{c}\text { Flyover Condition } \\
\text { M0.225/2100ft PC35 }\end{array}$ & $\begin{array}{c}\text { Approach Condition } \\
\text { M0.218/394ft PC21 }\end{array}$ & $\begin{array}{l}\text { Relationship } \\
\text { to Source }\end{array}$ \\
\hline \multicolumn{5}{|l|}{ Slot nozzles (12) } \\
\hline$W$, in & 60.0 & 60.0 & 60.0 & \multirow{6}{*}{$\begin{array}{l}\text { Slot nozzle } \\
\text { jet noise }\end{array}$} \\
\hline$H$, in & 32.8 & 34.0 & 38.2 & \\
\hline$A R$ & 1.83 & 1.76 & 1.57 & \\
\hline Nozzle total $T,{ }^{\circ} \mathrm{R}$ & 567 & 552 & 547 & \\
\hline Nozzle $V, \mathrm{ft} / \mathrm{s}$ & 593 & 464 & 283 & \\
\hline Nozzle pressure ratio & 1.21 & 1.12 & 1.04 & \\
\hline \multicolumn{5}{|l|}{ Fan Propulsors (12) } \\
\hline Flow rate, $\mathrm{lb} / \mathrm{s}$ & 577 & 453 & 326 & \multirow{4}{*}{ Fan noise } \\
\hline Shaft speed, rpm & 3531 & 2836 & 1917 & \\
\hline Fan pressure ratio & 1.19 & 1.11 & 1.05 & \\
\hline Helical tip $M$ & 0.930 & 0.737 & 0.486 & \\
\hline \multicolumn{5}{|l|}{ Turboshafts (2) } \\
\hline Core flow rate, $\mathrm{lb} / \mathrm{s}$ & 90.7 & 60.4 & 36.4 & \multirow{8}{*}{$\begin{array}{l}\text { Turboshaft } \\
\text { core noise, } \\
\text { tailpipe jet } \\
\text { noise }\end{array}$} \\
\hline Burner inlet total $p$, psia & 839 & 518 & 278 & \\
\hline Burner inlet total $T,{ }^{\circ} \mathrm{R}$ & 1778 & 1601 & 1382 & \\
\hline Burner exit total $T,{ }^{\circ} \mathrm{R}$ & 3312 & 2851 & 2250 & \\
\hline Overall pressure ratio & 59.2 & 38.1 & 19.2 & \\
\hline Turbine $\zeta$ ratio & 0.0321 & 0.0452 & 0.0810 & \\
\hline Tailpipe $V_{\text {exit }}, \mathrm{ft} / \mathrm{s}$ & 752 & 480 & 244 & \\
\hline Tailpipe exit total $T,{ }^{\circ} \mathrm{R}$ & 1365 & 1251 & 1112 & \\
\hline
\end{tabular}

categorized by their relevance to each noise source. The engine state information is used to predict component source noise spectra as described throughout Section II.

\section{Shielding Benefits}

Insertion loss spectra are calculated as described in Section II.F for every source-observer geometry at halfsecond intervals along the trajectory. These spectra are subtracted from the propulsor fan noise sources as the vehicle is analytically flown past each observation monitor. The resulting overall sound pressure level (OASPL) vs. time histories for the shielded and unshielded configurations are shown in Figure 15 for the approach and lateral observers. The results shown in the figure apply to the initial N3-X configuration (i.e., Figure 2, top) with no trailing edge pitch effector. The times of closest proximity to the approach and lateral certification monitors occur at -28 seconds and 62 seconds, respectively.
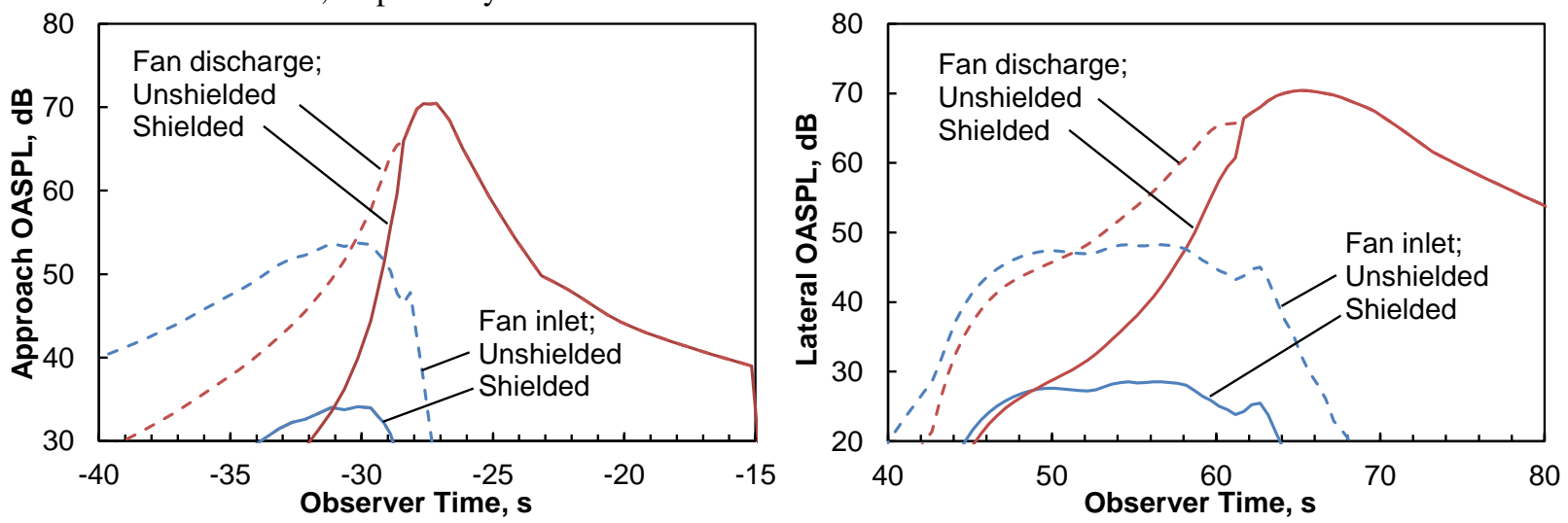

Figure 15. Propulsor fan-planform shielding benefit; approach observer (left) and lateral observer (right).

The large N3-X planform area effectively eliminates all of the forward-radiated fan propulsor noise. All of the noise originating from the fan inlet is reduced to levels that are greatly overshadowed by other sources. For the flyover and approach observers (located on the extended runway centerline), the bulk of the forward shielding effectiveness is provided by the large distance to the planform leading edge around which the source noise must

16 of 22

American Institute of Aeronautics and Astronautics 
diffract. There also appears to be effective forward shielding at the lateral observation station, where the sound must diffract around the span of the wing to reach the monitor.

Fan discharge noise shielding is much less effective, at least for the initial N3-X configuration where the fan flow exits at the planform trailing edge. Nevertheless, there is some diffraction benefit apparent from Figure 15, until the sources move from the shadow zone to the bright zone (i.e., from positive to negative Fresnel numbers). The low-noise N3-X configuration (Figure 2, bottom) has a pitch effector that provides more fan discharge noise shielding, but being similar, those results are not plotted.

\section{Initial N3-X Configuration Results}

Results for the initial N3-X configuration (Figure 2, top) are presented first. The OASPL and tone-corrected perceived noise level (PNLT) noise-time histories are plotted in Figure 16 through Figure 18 for the lateral, flyover, and approach observers, respectively. Observer time relative to the point of brake release (or touchdown) is used as the independent parameter in each figure. ANOPP has the ability to compute each noise source separately from the others. Plotting the levels of each source as a function of time provides additional insight to the overall problem. The OASPL metric is shown at the left in each figure because of its simplicity and its ability to clearly show the smooth rise and fall of each noise source over time. The PNLT metric - shown at the right in each figure - has qualities that capture level, frequency weighting, and tone annoyance penalties. The PNLT-time history within the integration region of $10 \mathrm{PNdB}$ from the maximum PNLT (shown as a horizontal line in each right-hand figure) is the regulatory basis for the EPNL. The PNLT histories are much more irregular than the OASPL histories: as the airplane approaches and recedes, Doppler and convective amplification effects and pseudotone activity from ground reflections have an irregular effect on tone correction penalties.
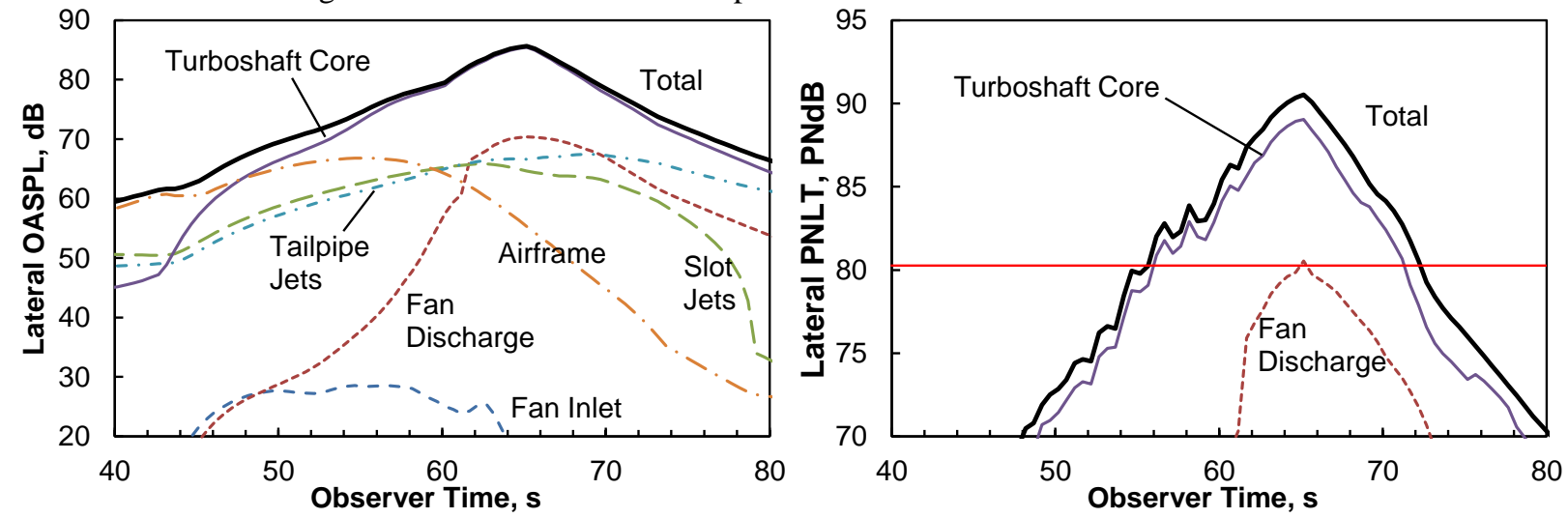

Figure 16. Lateral observer OASPL noise-time histories (left), and PNLT noise-time histories (right).
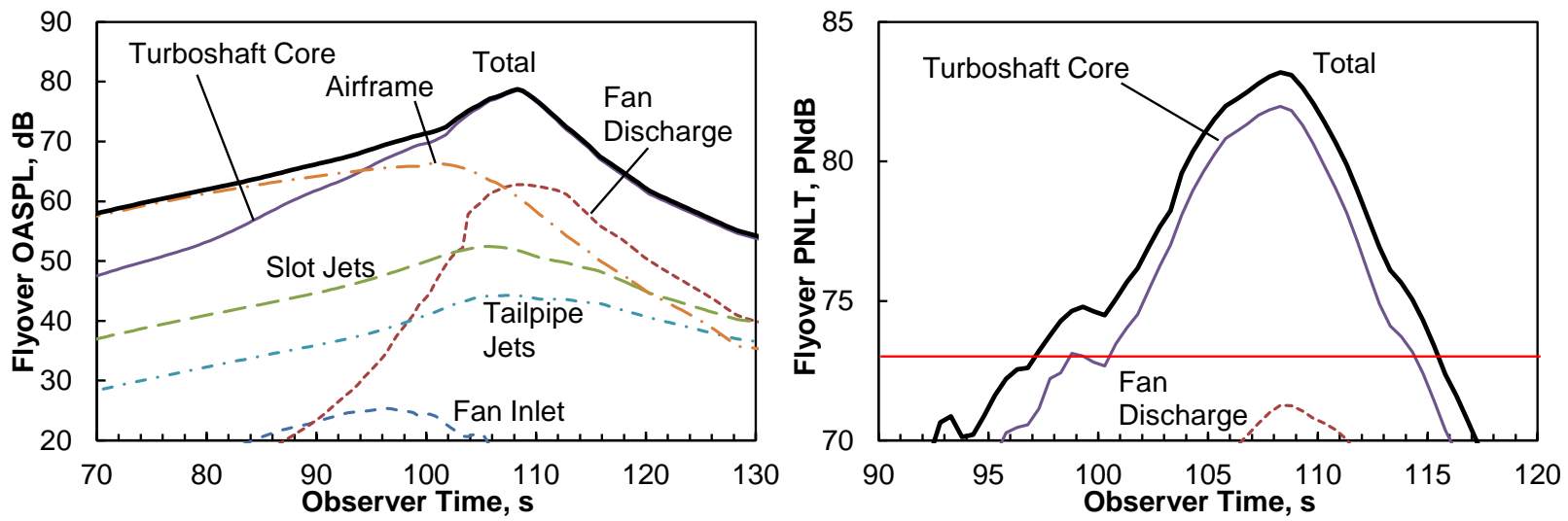

Figure 17. Flyover observer OASPL noise-time histories (left), and PNLT noise-time histories (right).

17 of 22

American Institute of Aeronautics and Astronautics 

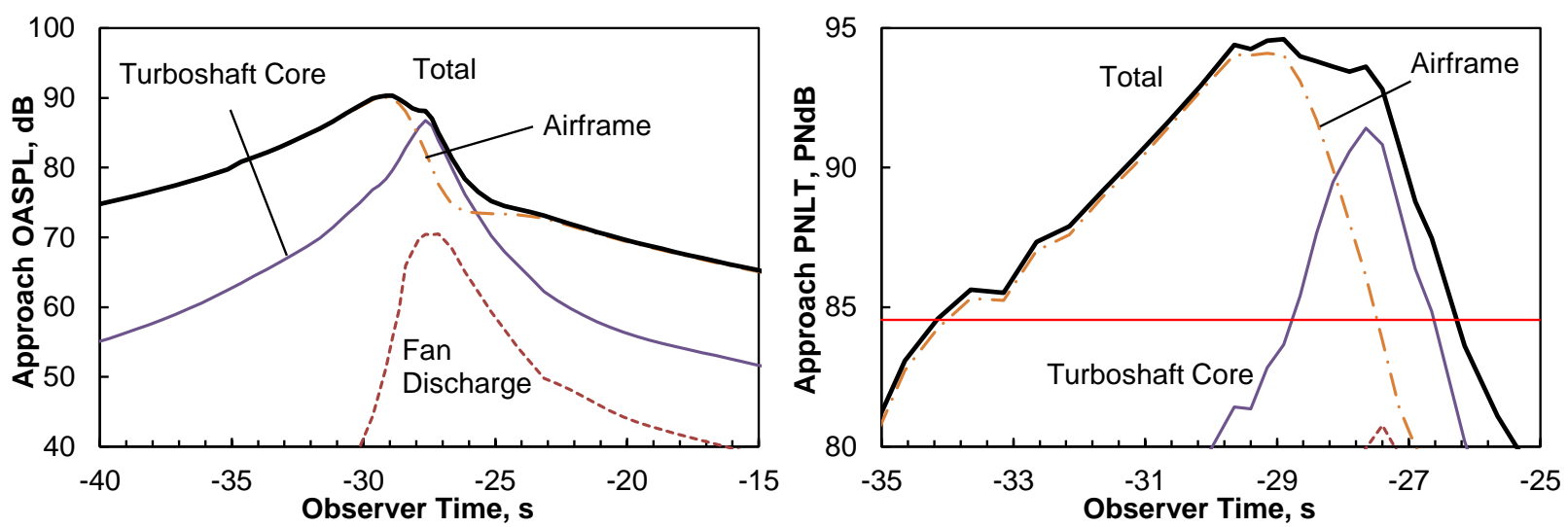

Figure 18. Approach observer OASPL noise-time histories (left), and PNLT noise-time histories (right).

Noise at the lateral monitor is dominated by turboshaft core noise. There is a minor contribution from the propulsor fan discharge noise. There also appears to be some pseudotone activity due to ground reflections that precedes the maximum PNLT. Jet noise and airframe noise may appear in Figure 16 to contribute to the overall noise signature on an OASPL basis, but unlike fan noise they are broadband sources and do not significantly impact the PNLT metric.

Noise at the flyover monitor is also dominated by turboshaft core noise. Once again, there is a minor contribution from fan discharge noise. There is also a minor contribution from airframe noise early in the history, even with gear retracted and with minimal flaps extended. The noise abatement throttle cutback occurs 87 seconds after brake release. The effects of this can be seen in Figure 17 by slight dip in core noise just prior to the PNLT integration region. The flyover EPNL could probably be reduced somewhat by optimizing the timing of the throttle cutback, as permitted by regulations. ${ }^{54}$

Airframe noise dominates on approach. But even at the lower approach engine throttle setting,

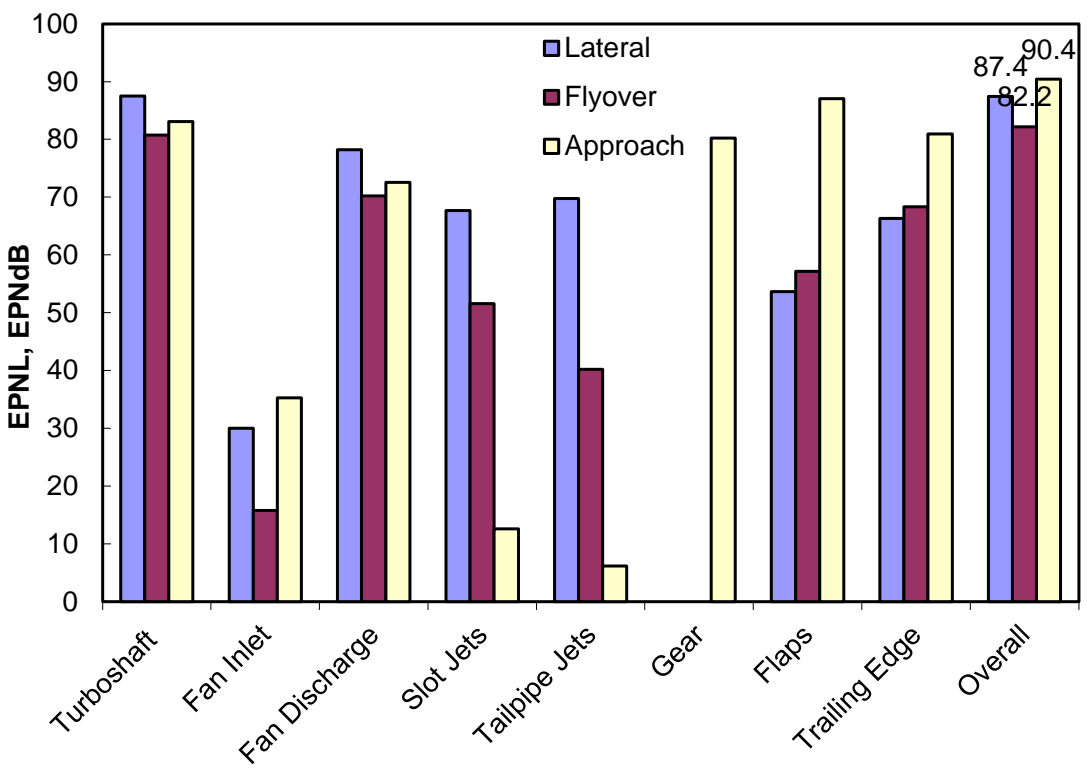

Figure 19. Initial N3-X configuration: certification noise predictions. core noise from the turboshaft engines also contributes to the EPNL. Source noise directivity plays a role in this, which can be seen in Figure 18: the aft-radiated core noise contributes to the EPNL after the airframe noise has peaked.

The EPNLs of the initial N3-X configuration are shown in Figure 19. Lateral, flyover, and approach EPNLs are $87.4,82.2$, and 90.4EPNdB, respectively. The dominant noise source at the lateral and flyover condition is the turboshaft engine core noise, even with core acoustic liners and power turbines providing additional core noise reduction. The dominant noise source on approach is flap noise. Forward shielding of the propulsor fan noise is very effective; but rearward shielding of fan discharge noise is much less effective. The predicted cumulative margin to the Chapter 4 rule is $32 \mathrm{EPNdB}$. This meets NASA's N+1 Fixed Wing noise goal, but it falls short of the N+2 $(-42 \mathrm{EPNdB})$ and the $\mathrm{N}+3(-52 \mathrm{EPNdB})$ noise goals.

4. Low-Noise N3-X Configuration Results

As discussed in Section II, the special low-noise configuration of the N3-X (Figure 2, bottom) is intended to address the dominant noise sources that became evident after the noise levels of the first configuration were examined. The loud turboshaft engines are relocated from the wingtips to an alternate location; perhaps somewhere

18 of 22

American Institute of Aeronautics and Astronautics 
on the upper surface of the planform where they can enjoy shielding from the large wingbody planform, or perhaps embedded inside the wingbody volume with inlet and exhaust ducts long enough where acoustic treatment can reduce the core noise to acceptable levels. If relocating the turboshaft engines is not practicable and they must remain mounted on the wingtips, they could be designed with lower overall pressure ratios. This of course would result in a performance penalty, but it would serve to reduce turboshaft core noise as well as LTO $\mathrm{NO}_{\mathrm{X}}$. In any event, the core noise is set to zero for the low-noise configuration. The turboshaft tailpipe jet noise, however, is an unshielded distributed source and it is assumed to be present in both configurations.

The horizontal pitch effector is reintroduced in this variant - and the resulting increase in slotted jet noise tolerated - in order to provide additional noise shielding for the fans. The pitch effector is assumed to extend 10 feet beyond the slot nozzle exit and it creates a greater amount of diffraction. Last, the conventional slotted flap system is replaced with lownoise, slotless flaperons to address the noise at approach. The flaperon high-lift system noise is assumed to be low enough to be ignored.

The EPNLs of the lownoise variant are shown in Figure 20. The results of the initial configuration are "ghosted" alongside in the figure for comparison purposes. Lateral, flyover, and approach EPNLs are 75.5, 68.9, and 83.8EPNdB, respectively. The pitch effector is much more effective in shielding propulsor fan discharge noise. Propulsor fan discharge noise replaces the turboshaft core as the loudest lateral noise source. Landing gear and the trailing edge clean airframe noise vie for the loudest approach noise source. When the turboshaft core noise is suppressed, the trailing edge clean airframe noise is the loudest flyover noise source.

The N3-X noise predictions are plotted against maximum takeoff gross weight in Figure 21. Although there would be differences in gross weight

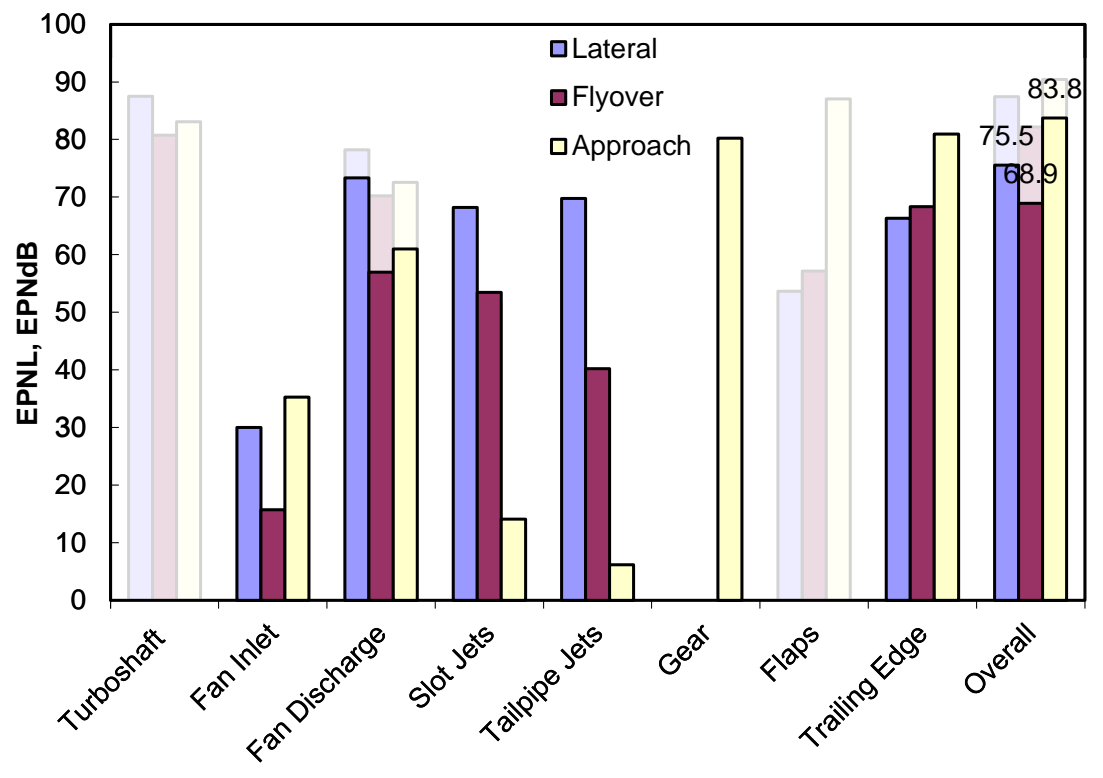

Figure 20. Low-noise N3-X configuration: certification noise predictions.

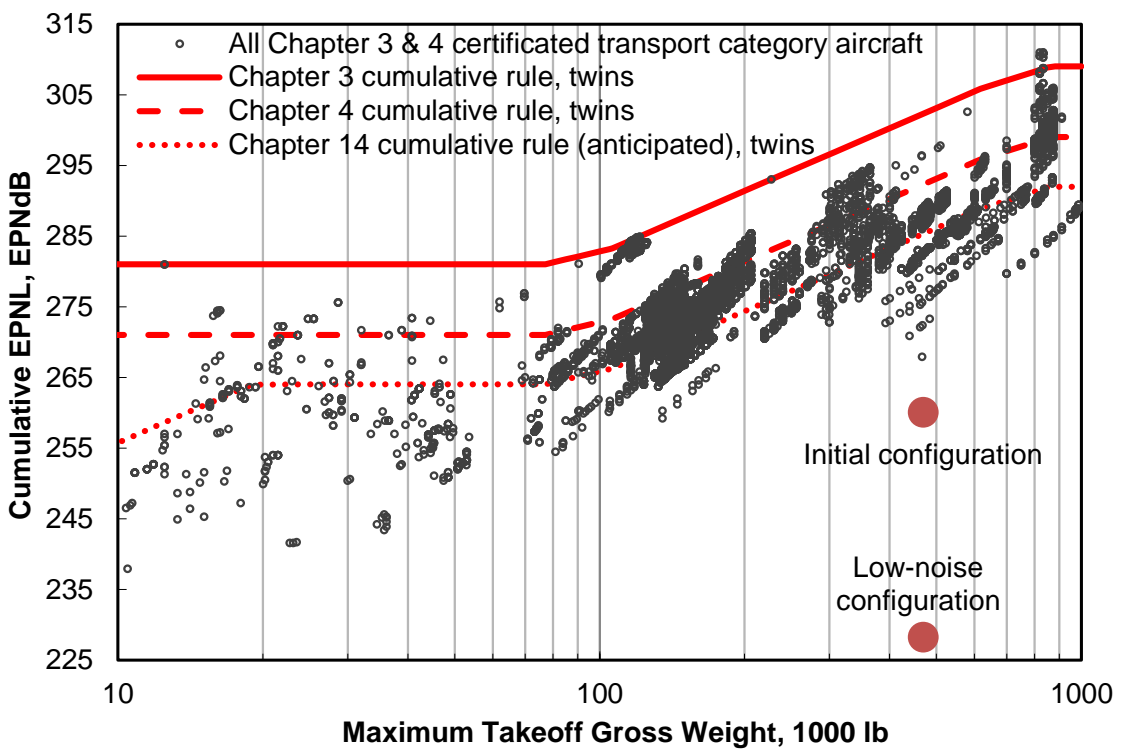

Figure 21. N3-X noise predictions relative to ICAO noise standards and certification data. between the two N3-X variants, they are both plotted in the figure at 470,000lb. Also shown in the plot are the ICAO Chapter 3, Chapter 4 and the anticipated Chapter 14 noise standards for transport category, twin-engine, subsonic airplanes. The Chapter 14 standard is anticipated to be in effect for applicants of type certificates with maximum takeoff weights equal to or

19 of 22

American Institute of Aeronautics and Astronautics 
greater than 55 metric tonnes by 31 December 2017, and by 31 December 2020 for applicants with maximum takeoff weights less than 55 metric tonnes. Also plotted are data for all Chapter 3 and Chapter 4 certificated transport category aircraft. ${ }^{55}$ Both versions of the N3-X exceed the cumulative noise margin of any currently certified airplane. Overall, the N3-X vehicle redesign strategy is effective: with the low-noise variant, the N3-X Chapter 4 cumulative margin improves from 32 to $64 \mathrm{EPNdB}$. This exceeds the Fixed Wing Project's $\mathrm{N}+3$ noise goal by $12 \mathrm{EPNdB}$.

\section{Conclusions}

Preliminary analytical predictions of certification noise and exhaust emissions for NASA's N3-X transport are presented in this paper. The noise and exhaust emission results presented here are generated using NASA's systems analysis tools with several key modifications to accommodate this unconventional architecture.

Predictions for landing and takeoff $\mathrm{NO}_{\mathrm{X}}$ are estimated to be 85 percent less than the Tier 6-CAEP/6 standard. This exceeds NASA's $\mathrm{N}+3$ environmental goal for local air quality by five percent.

Two N3-X variants are evaluated for certification noise. The first is estimated to have a Chapter 4 cumulative margin of 32EPNdB. The second variant addresses the loudest noise sources discovered during the analysis of the first configuration. This low-noise configuration is estimated to have a Chapter 4 cumulative margin of 64EPNdB, exceeding NASA's $\mathrm{N}+3$ environmental goal for community noise by $12 \mathrm{EPNdB}$.

The N3-X transport is an innovative concept using aggressive technologies that appears to satisfy the Fixed Wing Project's goals for block fuel burned, landing and takeoff $\mathrm{NO}_{\mathrm{X}}$ emissions, and certification noise. It represents one potential pathway to achieving NASA's long-term aeronautics goals.

\section{Acknowledgments}

Thanks to NASA's Fixed Wing Project for supporting this study and to James Felder at NASA Glenn Research Center for providing the turboelectric distributed propulsion system simulation used in this study.

\section{References}

${ }^{1}$ Felder, J.; Kim, H.; and Brown, G.: "Turboelectric Distributed Propulsion Engine Cycle Analysis for Hybrid-Wing-Body Aircraft," $47^{\text {th }}$ AIAA Aerospace Sciences Meeting Including The New Horizons Forum and Aerospace Exposition, AIAA 20091132, Orlando, Florida, January, 2009.

${ }^{2}$ Kim, H., "Distributed Propulsion Vehicles," $27^{\text {th }}$ International Congress of the Aeronautical Sciences, ICAS 2010.

${ }^{3}$ Warwick, G.: "Fuel-Sipper - the Turboelectric Flying Wing," Aviation Week \& Space Technology, May 25, 2011 [URL: http://www.aviationweek.com/Blogs.aspx?plckPostId=Blog:a68cb417-3364-4fbf-a9dd-4feda680ec9cPost:ea7a1fa9-2129-4c67a93c-52ca6bda8e81, accessed July 17, 2013].

${ }^{4}$ Felder, J.; Brown, G.; and Kim, H.: "Turboelectric Distributed Propulsion in a Hybrid Wing Body Aircraft," ISABE-20111340, 2011.

${ }^{5}$ Felder, J.; Tong, M.; and Chu, J.: "Sensitivity of Mission Energy Consumption to Turboelectric Distributed Propulsion Design Assumptions on the N3-X Hybrid Wing Body Aircraft," 48 ${ }^{\text {th }}$ AIAA/ASME/SAE/ASEE Joint Propulsion Conference \& Exhibit, AIAA-2012-3701, Atlanta, Georgia, August 2012.

${ }^{6}$ Armstrong, M.; Ross, C.; Blackwelder, M.; and Rajashekara, K.: "Trade Studies for NASA's N3-X Turboelectric Distributed Propulsion System Electrical Power System Architecture,” SAE Int. J. Aerosp., Vol. 5, no. 2, pp. 325-336, 2012, doi: 10.4271/2012-01-2163.

${ }^{7}$ Mankins, J.: "Technology Readiness Levels: A White Paper," Advanced Concepts Office, NASA Office of Space Access and Technology, April 6, 1995 [URL: http://www.hq.nasa.gov/office/codeq/trl/trl.pdf, accessed Nov. 14, 2013].

${ }^{8}$ U.S. Code of Federal Regulations, Title 14, Chapter I, Part 34, "Fuel Venting and Exhaust Emission Requirements for Turbine Engine Powered Airplanes."

${ }^{9}$ International Standards and Recommended Practices - Environmental Protection, "Annex 16 to the Convention on International Civil Aviation, Volume II: Aircraft Engine Emissions," $5^{\text {th }}$ Edition, International Civil Aviation Organization (ICAO), Montreal, Canada, July 2008.

${ }^{10}$ U.S. Code of Federal Regulations, Title 14, Chapter I, Part 36, "Noise standards: Aircraft Type and Airworthiness Certification."

${ }^{11}$ International Standards and Recommended Practices - "Environmental Protection, Annex 16 to the Convention on International Civil Aviation, Volume I: Aircraft Noise," $5^{\text {th }}$ Edition, International Civil Aviation Organization (ICAO), Montreal, Canada, July 2008.

${ }^{12}$ Bridges, J.: "Acoustic Measurements of Rectangular Nozzles with Bevel," $18^{\text {th }}$ AIAA/CEAS Aeroacoustics Conference (33 ${ }^{\text {rd }}$ AIAA Aeroacoustics Conference), AIAA-2012-2252, Colorado Springs, CO, 2012.

${ }^{13}$ Coles, W.D.: "Jet-Engine Exhaust Noise from Slot Nozzles," NASA TN D-60, 1959.

${ }^{14}$ Gillian, R.E.: “Aircraft Noise Prediction Program User's Manual,” NASA TM-84486, 1983. 
${ }^{15}$ Zorumski, W.E.: “Aircraft Noise Prediction Program Theoretical Manual," NASA TM-83199, 1981, Parts 1 and 2 (Currently maintained at NASA Langley Research Center by the ANOPP team in electronic format and provided upon request; Latest revision: July, 2013).

${ }^{16}$ Claus, R.W.; Evans, A.L.; Lytle, J.K.; and Nichols, L.D.: "Numerical Propulsion System Simulation," Computing Systems in Engineering, Vol. 2, No. 4, 1991, pp. 357-364. doi:10.1016/0956-0521(91)90003-N.

${ }^{17}$ NPSS, Numerical Propulsion System Simulation, Software Package, Ver. 1.6.5, NASA, 2008.

${ }^{18}$ Onat, E.; and Klees, G.: "A Method to Estimate Weight and Dimensions of Large and Small Gas Turbine Engines,” NASA CR-159481, 1979.

${ }^{19}$ Rink, K.K.; and Lefebvre, A.H.: "The Influence of Fuel Composition and Spray Characteristics on Nitric Oxide Formation," Combustion, Science and Technology, vol. 68, 1989, pp. 1-14. doi:10.1080/00102208908924066.

${ }^{20}$ Correa, S.M.: "Lean Premixed Combustion for Gas Turbines: Review and Required Research," Fossil Fuel Combustion, ASME PD, vol. 33, 1991.

${ }^{21}$ Leonard, G.L.; and Correa, S.M.: "NO${ }_{\mathrm{X}}$ Formation in Lean Premixed High-Pressure Methane Flames," Second ASME Fossil Fuel Combustion Symposium, PD-30, 1990, pp. 69-74.

${ }^{22}$ Stone, J.R., Krejsa, E.A., Clark, B.J., and Berton, J.J.: "Jet Noise Modeling for Suppressed and Unsuppressed Aircraft in Simulated Flight," NASA TM-2009-215524, 2009.

${ }^{23}$ Bridges, J.E.; Khavaran, A.K.; and Hunter, C.A.: “Assessment of NASA's Aircraft Noise Prediction Capability, Chapter 8: Jet Noise Prediction,” NASA TP-2012-215653, July, 2012.

${ }^{24}$ Weir, D.S., editor: "Engine Validation of Noise and Emission Reduction Technology, Phase I," Honeywell Report No. 21 13843, Honeywell Aerospace, Phoenix, AZ; also NASA CR-2008-215225, 2008.

${ }^{25}$ Society of Automotive Engineers: "Method for Calculating Attenuation of Aircraft Ground Noise Propagation During Takeoff and Landing," Aerospace Information Report AIR-923, August, 1966.

${ }^{26}$ Rawls, J.: “ACD Module,” ANOPP Theoretical Manual, level 30, NASA Langley Research Center, Hampton, VA, 2011.

${ }^{27}$ Kontos, K.B., Janardan, B., and Gliebe, P.R., "Improved NASA-ANOPP Noise Prediction Computer Code for Advanced Subsonic Propulsion Systems Volume 1: ANOPP Evaluation and Fan Noise Model Improvement," NASA CR-195480, 1996.

${ }^{28}$ Heidmann, M.F.: "Interim Prediction Method for Fan and Compressor Source Noise," NASA TMX-71763, 1979.

${ }^{29}$ Dittmar, J.H., Elliott, D.M., and Bock, L.A., "Some Acoustic Results from the Pratt and Whitney Advanced Ducted Propulsor - Fan 1,” NASA TM-1999-209049, 1999.

${ }^{30}$ Kontos, K.B., Kraft, R.E., and Gliebe, P.R., "Improved NASA-ANOPP Noise Prediction Computer Code for Advanced Subsonic Propulsion Systems. Volume 2: Fan Suppression Model Development,” NASA CR-202309, 1996.

${ }^{31}$ Emmerling, J.J.; Kazin, S.B.; and Matta, R.K.: "Core Engine Noise Control Program. Volume III, Supplement 1 -

Prediction Methods," FAA-RD-74-125, III-I, Mar. 1976 (Available from DTIC as AD A030 376.).

${ }^{32}$ Ho, P.Y.; and Doyle, V.L.: "Combustion noise prediction update," $5^{\text {th }}$ AIAA Aeroacoustics Conference, Seattle, WA, AIAA Paper 1979-0588, 1979.

${ }^{33}$ Hultgren, L.; Miles, J.; and Jorgenson, P.: “Assessment of NASA's Aircraft Noise Prediction Capability, Chapter 3: Engine System and Core Noise,” NASA TP-2012-215653, July, 2012.

${ }^{34}$ Hultgren, L.: "Full-Scale Turbofan-Engine Turbine-Transfer Function Determination Using Three Internal Sensors," AIAA2011-2912, NASA/TM-2012-217252, February 2012.

${ }^{35}$ Guo, Y.: Empirical Prediction of Aircraft Landing Gear Noise, NASA CR-2005-213780, Boeing Phantom Works, Long Beach, CA, July 2005.

${ }^{36}$ Guo, Y.: An Improved Landing Gear Noise Prediction Scheme, NASA CR NAS1-NNL04AA11B Task NNL06AB63T, The Boeing Company, Huntington Beach, CA, November 2006.

${ }^{37}$ Caspar, J.H, et al.: "Assessment of NASA's Aircraft Noise Prediction Capability, Chapter 4: Airframe Noise: A Prediction Capability Assessment," NASA TP-2012-215653, July, 2012.

${ }^{38}$ Berton, J.; Envia, E.; and Burley, C.: “An Analytical Assessment of NASA's N+1 Subsonic Fixed Wing Project Noise Goal," AIAA Paper 2009-3144, $15^{\text {th }}$ AIAA/CEAS Aeroacoustics Conference (30 ${ }^{\text {th }}$ AIAA Aeroacoustics Conference), Miami, FL, 11-13 May, 2009.

${ }^{39}$ Fink, M.R.: “Airframe Noise Prediction Method,” FAA-RD-77-29, March, 1977.

${ }^{40}$ Maekawa, Z.: "Noise Reduction By Screens," Memoirs of the Faculty of Engineering, Vol. 12, Kobe University, Kobe, Japan, 1966, pp. 472-479.

${ }^{41}$ Beranek, L.L.: "Noise and Vibration Control," McGraw-Hill, New York, 1971, pp. 174-180.

${ }^{42}$ Mitchell, J.; Barton, C.; Kisner, L.; and Lyon, C.: "Computer Program to Predict Noise Levels of General Aviation Aircraft: User's Guide," NASA CR-168050, 1982.

${ }^{43}$ Weir, D.: "WING Module," ANOPP Theoretical Manual, level 17, NASA Langley Research Center, Hampton, VA.

${ }^{44}$ Kawai, R.; Brown, D.; Roman, D.; and Odle, R.: "Acoustic Prediction and Test Validation for an Efficient Low-Noise Hybrid Wing Body Subsonic Transport," Boeing Phantom Works, NASA Contract NNL07AA54C ELNHWB N+2 Phase I Final Report PWDM08-0006A, Oct. 30, 2008.

${ }^{45}$ U.S. Code of Federal Regulations, Title 14, Chapter I, Part 25, Airworthiness Standards: Transport Category Airplanes.

${ }^{46}$ Kumasaka, H.; Martinez, M.; and Weir, D.: "Definition of 1992 Technology Aircraft Noise Levels and the Methodology for Assessing Airplane Noise Impact of Component Noise Reduction Concepts,” NASA CR-198298, June, 1996.

21 of 22

American Institute of Aeronautics and Astronautics 
${ }^{47}$ Society of Automotive Engineers: "Standard Values of Atmospheric Absorption as a Function of Temperature and Humidity," Aerospace Recommended Practice 866, 1964.

${ }^{48}$ Chien, C.F.; and Soroka, W.W.: "Sound Propagation Along an Impedance Plane," J. Sound and Vibration, vol. 43, no. 1, Nov. 8, 1975, pp. 9-20.

${ }^{49}$ Delany, M.E.; and Bazley, E.N.: “Acoustical Properties of Fibrous Absorbent Materials,” Applied Acoustics, vol. 3, no. 2, Apr., 1970, pp.105-116.

${ }^{50}$ Embleton, T.F.W.; Piercy, J.E.; and Daigle, G.A.: "Effective Flow Resistivity of Ground Surfaces Determined by Acoustical Measurements," J. Acoustical Society of America, vol. 74, no. 4, 1983, pp. 1239-1244.

${ }^{51}$ Society of Automotive Engineers: "Method for Predicting Lateral Attenuation of Airplane Noise," Aerospace Information Report 5662, April, 2006.

${ }^{52}$ U.S. Code of Federal Regulations, Title 40, Chapter I, Subchapter C, Part 87, "Control of Air Pollution from Aircraft and Aircraft Engines."

${ }^{53}$ International Civil Aviation Organization (ICAO): “Aircraft Engine Emissions Databank,” European Aviation Safety Agency, Environmental Protection [URL: http://www.easa.europa.eu/environment/edb/introduction.php, accessed July 15, 2013].

${ }^{54}$ International Civil Aviation Organization (ICAO), Committee on Aviation Environmental Protection: "Environmental Technical Manual, Volume I, Procedures for the Noise Certification of Aircraft,” Based on Doc. 9501, vol. I, $1^{\text {st }}$ ed., July 2012.

${ }^{55}$ International Civil Aviation Organization (ICAO): "Noise Type Certificates," European Aviation Safety Agency, Certification Directorate [URL: http://www.easa.europa.eu/certification/type-certificates/noise.php, accessed July 15, 2013]. 